Dahm, T., Heimann, S., Metz, M., Isken, M. P. (2021): A self-similar dynamic rupture model based on the simplified wave-rupture analogy. Geophysical Journal International, 225, 3, 1586-1604.

https://doi.org/10.1093/gji/ggab045 


\title{
A self-similar dynamic rupture model based on the simplified wave-rupture analogy
}

\author{
T. Dahm ${ }^{\oplus},{ }^{1,2}$ S. Heimann, ${ }^{1}$ M. Metz ${ }^{1,2}$ and M.P. Isken ${ }^{1,2,3}$ \\ ${ }^{1}$ GFZ German Research Centre for Geosciences, Physics of Earthquakes and Volcanoes, 14473 Potsdam, Germany.E-mail: dahm@gfz-potsdam.de \\ ${ }^{2}$ Institute of Geosciences, University of Potsdam, 14476 Potsdam, Germany \\ ${ }^{3}$ Institute for Geoscience, University of Kiel, 24118 Kiel, Germany
}

Accepted 2021 February 1. Received 2021 January 26; in original form 2020 May 11

\begin{abstract}
SUMMAR Y
The investigation of stresses, faults, structure and seismic hazards requires a good understanding and mapping of earthquake rupture and slip. Constraining the finite source of earthquakes from seismic and geodetic waveforms is challenging because the directional effects of the rupture itself are small and dynamic numerical solutions often include a large number of free parameters. The computational effort is large and therefore difficult to use in an exploratory forward modelling or inversion approach. Here, we use a simplified self-similar fracture model with only a few parameters, where the propagation of the fracture front is decoupled from the calculation of the slip. The approximative method is flexible and computationally efficient. We discuss the strengths and limitations of the model with real-case examples of well-studied earthquakes. These include the $M_{\mathrm{w}} 8.32015 \mathrm{Illapel}$, Chile, megathrust earthquake at the plate interface of a subduction zone and examples of continental intraplate strike-slip earthquakes like the $M_{\mathrm{w}} 7.12016$ Kumamoto, Japan, multisegment variable slip event or the $M_{\mathrm{w}} 7.52018$ Palu, Indonesia, supershear earthquake. Despite the simplicity of the model, a large number of observational features ranging from different rupture-front isochrones and slip distributions to directional waveform effects or high slip patches are easy to model. The temporal evolution of slip rate and rise time are derived from the incremental growth of the rupture and the stress drop without imposing other constraints. The new model is fast and implemented in the open-source Python seismology toolbox Pyrocko, ready to study the physics of rupture and to be used in finite source inversions.
\end{abstract}

Key words: Earthquake dynamics; Earthquake ground motions; Earthquake hazards; Earthquake source observations.

\section{INTRODUCTION}

Earthquake rupture, a sudden failure of rock along faults releasing internal stresses, is a complex, multifacetted process that involves a broad range of temporal and spatial scales. The study of rupture gives insights to several key parameters in seismology. It allows to discriminate the fault and auxiliary plane (e.g. Cesca et al. 2011a,b; Lopez-Comino \& Cesca 2016) and helps to identify active faults. It can lead to estimates of stress and stress gradients on buried faults (e.g. Dahm et al. 2010, 2015; Lui \& Huang 2019), and possibly identify asperities and barriers where large variations of stress or strength occur (e.g. Meng et al. 2018). The slip and slip rate, and directional effects associated with the rupture affects ground motions generated by earthquakes (e.g. Somerville et al. 1997), and thus impacts the assessment of seismic hazard in a region (e.g. Rowshandel 2006).

The rupture nucleation at the microscopic level is confined to a small volume surrounding the future nucleation point (e.g.
Ohnaka 2013). It is a slow process that can take weeks or months prior to the earthquake. The co-seismic fracture itself is fast and propagates almost at the speed of elastic shear waves over long distances of the fault. Immediately after the fracture front has passed a point on the fault, the co-seismic dislocation (slip) of the two adjacent (cut) blocks is starting to grow over some time, at maximum until the rupture front has stopped everywhere to propagate. After the earthquake, post-seismic slip may still occur over the whole plane in the following weeks or months. Earthquake rupture studies aim to resolve this complex process and to simulate, or estimate, the slip on the rupture plane as a function of space and time at all scales, from microseconds to months and from a few centimetres to several hundreds of kilometres.

Simulating the radiating waves from a kinematic rupture model is straight forward. For instance, the assumed fault plane is gridded in rectangular or triangular subfaults and for each oriented subfault the slip magnitude and orientation as a function of time is 
prescribed. Each subfault is considered as point source which radiates waves, by means of a Green's function approach, and the overall wave propagation towards a station is the superposition of all subfault contributions. The kinematic modelling can be turned into an inversion approach, to retrieve time-dependent slip distributions from observed waveforms and displacements. Although this is formally possible if the data cover a sufficient range of azimuth and distance, the inversion is often highly non-unique (underdetermined) and therefore interpretation and comparison is problematic (e.g. Beresnev 2003; Mai et al. 2016). A common approach to resolve the non-uniqueness is to minimize the length of the solution and to introduce Laplacian smoothing, slip positivity, sparsitivity and other constraints. However, unphysical constraints and a predefined geometry do impact the best models and their uncertainties. Although several Bayesian inversion approaches were recently developed to handle the uncertainties in finite fault inversion (e.g. Minson et al. 2013; Shimizu et al. 2020, Heimann et al. 2018), including uncertainties related to Green's function (Yagi \& Fukahata 2011, Vasyura-Bathke et al. 2021), the effort of such methods is usually large which limits the approaches to the later detailed analysis long after the events.

Physics-based dynamic rupture models, which rely on few parameters only, are needed to allow a realistic forward modelling and to reduce the effort and non-uniqueness of the inversion. Our study develops a simplified, dynamic, semi-analytical rupture model suited for wavefield simulation and inversion. The rupture builds on the class of self-similar crack models (Kostrov 1964; Nielsen \& Madariaga 2003). On one hand it is approximative as it neglects inertia and so far the details of frictional effects, and treats the rupture front growth in a simplified way. On the other hand, it is complete as the slip fulfils the boundary condition on the broken plane for every instantaneous rupture front geometry and applied stress.

A simple dynamic rupture model has first been suggested by Brune (1970, 1971). It considers the sudden application of a shear stress pulse to a circular fault, but no rupture propagation. The instantaneous shear stress drop in the fault generates a plane $\mathrm{SH}$ wave propagating with velocity $v_{\mathrm{S}}$ perpendicular to the fault plane. Brune estimated the far-field displacement of the $S$ wave, ensuring that the low-frequency spectrum resembles the one of a double couple point source, and equated the amplitude spectra as a function of frequency and radius of the circular fault. The Brune's spectrum is used still today as a reference for estimating the size of an earthquake from the spectra of body waves. A more realistic circular crack rupture model was presented by Sato \& Hirasawa (1973). The authors assumed that the rupture propagates from the centre to the final radius of the fault with constant velocity $v_{\mathrm{r}}$. The slip is a function of stress drop and size of the growing circular crack. They assumed that slip has at any time the same form as that of a static crack with the size defined by the instantaneous rupture front. The model ensures that the final slip is consistent with a fracture mechanical static solution. Additional, variations of body-wave pulses in different directions to the fault and slip vector, the so-called directivity effects, are explained. Brune's amplitude spectra is reproduced for a far-distance station perpendicular to the plane, or by means of the average spectrum from all directions.

Numerical solutions to 3-D dynamic rupture problems commonly in use comprise finite difference (e.g. Madariaga et al. 1998), finite elements (e.g. Duan 2010), spectral elements (e.g. Kaneko et al. 2010) or unstructured discontinuous element methods (e.g. Tago et al. 2012). Such advanced modelling techniques are successfully used to study key aspects of ruptures, as for example the nucleation and arrest of induced earthquakes at reservoir level (e.g. Gallis et al. 2017; Buijz e et al. 2019). However, the exploitation of the model space with purely numerical approaches is computationally expensive. Our approach is to implement a semi-analytical, simple scheme efficient for fast simulations. We extend the simplified model by Sato \& Hirasawa (1973), where we relax the assumption of a constant rupture velocity and allow for arbitrary nucleation points and shapes of the rupture front. We calculate wave radiation in a layered half-space Earth model instead of a homogeneous full space, so that realistic rupture scenarios can be simulated. The extended model needs only few parameters in addition to a point source model.

Such a simplified rupture approach allows the simple and fast simulation of scenarios that can support our understanding of the physics of rupture. We show that the self-similar rupture model can reproduce the integrated waveform and parameters which are predicted by much more complex dynamic rupture models. So the seismic moment (Aki 1966), which is a product of average slip and area of the rupture plane, is robustly predicted. The source time function (STF), and derived parameters as the corner frequency and station specific apparent rise times of the STF, reproduce observations from real earthquakes without any constraints on rise time or rupture mode. Directivity effects and changes in apparent rupture velocity as a function of distance to the nucleation point can be explained, up to the extreme of apparent super-shear ruptures. The model can explain patches of high slip, as well as the backpropagation and reflection of slip at positions where stress changes. The energy of the rupture and the fracture toughness can be estimated as a function of time, allowing for future extensions to full fracture dynamic modelling.

\section{THEORY}

Fig. 1 shows two end-member kinematic shear rupture models to illustrate different modes of crack growth. A so-called crack-model is realized for a circular rupture with constant rupture velocity $v_{\mathrm{r}}$ (Fig. 2a; Sato \& Hirasawa 1973). The dislocation $\Delta u\left(r_{\mathrm{h}}, t\right)$ (slip) is growing as long as the rupture front propagates. It is largest at the centre of the crack and has an elliptical shape towards its tips. The slip rate $\Delta \dot{u}\left(r_{\mathrm{h}}, t\right)$ is non-zero at any time from the start to the stop of the rupture and everywhere on the ruptured pane. It is largest at the tip of the propagating crack and decreases towards the centre of the crack (Fig. 1a). A slip-pulse model is illustrated for a uni-directional rupture on a rectangular fault (Fig. 2b; Haskell $1964,1966,1969)$. In this model the slip rate is assumed to become zero at some distance behind the rupture front, so that the fault is at rest (heals) behind the rupture front and the slip reaches there its maximum value long before the rupture has stopped. The spatial pulse width can be defined by a constant rise time $T_{\mathrm{d}}$ times the rupture velocity. For instance, the self-healing on an infinite fault is modelled as a result of friction (e.g. Nielsen \& Carlson 2000; Nielsen \& Madariaga 2003).

The self-similar model developed in this paper combines both end-member rupture modes in a physical manner without imposing a frictional law and without any constraints on a rise time or healing front. We extend the concept of the self-similar circular crack of Sato \& Hirasawa (1973) to arbitrary geometries of finite faults. For the modelling, we treat the rupture front estimation independent of the slip model, and base the approach on two main assumptions:

(1) the shape of the rupture front can be approximated by the solution of the Eikonal equation with rupture velocity as field parameter; 
(a)

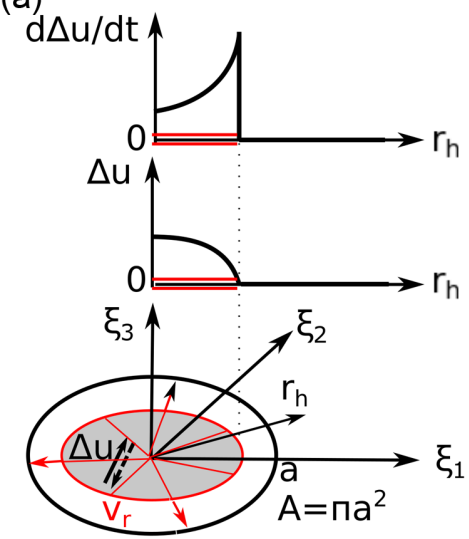

(b)

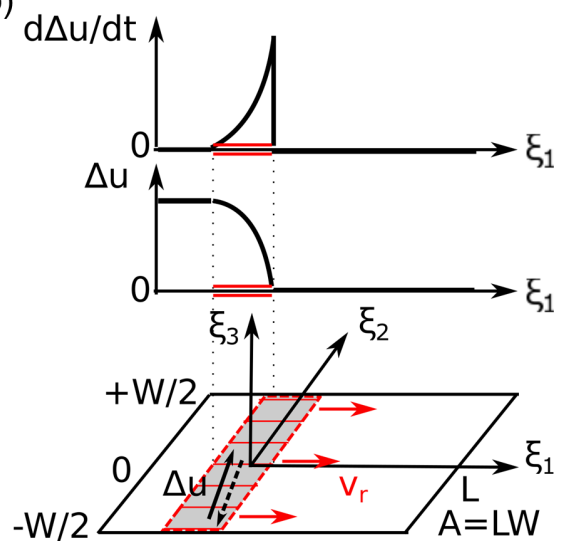

Figure 1. Sketch of two end-member kinematic shear rupture models. (a) Crack-model: circular rupture with constant rupture velocity $v_{\mathrm{r}}$ on a circular fault in the $\xi_{1}-\xi_{2}$ plane with radius $a$ (Sato \& Hirasawa 1973). The radial direction in the plane is $r_{\mathrm{h}}$. The azimuth of the time-dependent dislocation $\Delta u$ (slip) can have any but constant angle. The diagrams above the crack illustrate a snapshot of the slip and slip rate $(\Delta \dot{u}(t))$ as a function of $r_{\mathrm{h}}$ at the time of the reddish rupture front. (b) Slip-pulse model: uni-directional rupture in $\xi_{1}$ direction on a rectangular fault in the $\xi_{1}-\xi_{3}$ plane with length $L$ and width $W$ (e.g. Haskell $1964,1966,1969)$. The rupture front is a straight line. Slip and slip rate are plotted accordingly for a snapshot of a pulse-like rupture where only the grey band on the plane moves. The spatial centroid coordinates of both models are at $\xi=(0,0,0)^{T}$.

(a)

nucleation point rupture front
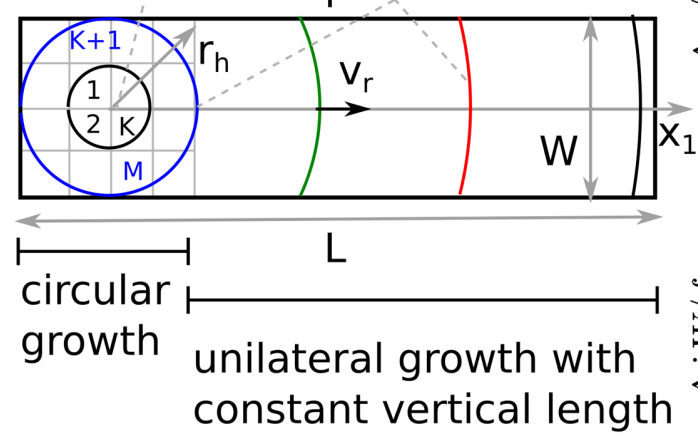

(b)
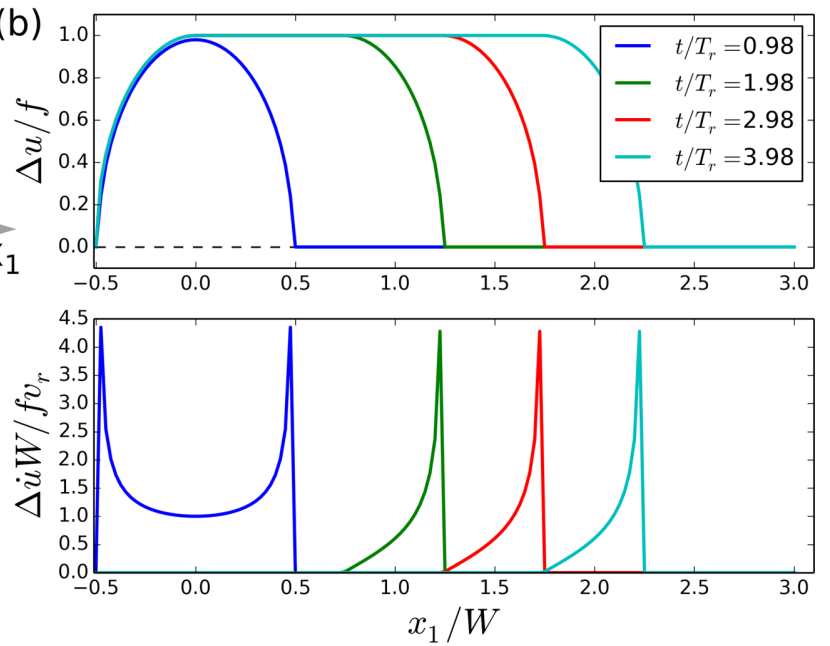

Figure 2. Illustration of the transition from crack-like growth to slip pulse growth for a vertical, rectangular crack. (a) Geometry of the rupture plane with width $W$ and length $L$. The grey lines and labels indicate the gridding for numerical implementation. Instantaneous rupture front isochrones are shown by coloured lines at different times $t / T_{\mathrm{r}}$ during rupture, where $T_{\mathrm{r}}=0.5 W / v_{\mathrm{r}}$ and $v_{\mathrm{r}}$ is the rupture velocity. During first phase (circular growth until $r_{\mathrm{h}}=W / 2$ ) the rupture front is circular. During the second phase (unilateral growth, $r_{\mathrm{h}} \gg W$ ) the rupture front in the centre of the crack propagates only in $x_{1}$ direction. (b) Quasi analytical solutions for the normalized dislocation $\Delta u$ (slip) and slip rate $\Delta \dot{u}$. The factor $f$ is based on the mode-II Griffith crack model and is $2(1-v) / \mathcal{N}$, where $v$ is the Poisson ratio and $\mathcal{N}$ the shear modulus. For $v \approx 0.45$ the factor of a circular crack equals the factor of an infinite Griffith crack-otherwise there is a small difference (not considered in the plot).

(2) the slip on the rupture plane is controlled by the instantaneous shape of the crack and the local, resolved shear stress.

As a first step, the fault orientation and the scalar moment are selected or estimated from the low-frequency content of waves in a centroid moment tensor point source inversion (e.g. Jost \& Herrman 1989; Dahm \& Krüger 2012, for review). The rupture front isochrones are calculated by iteratively solving the Eikonal equations of plumose lines in the rupture plane (Müller \& Dahm 2000; Heimann 2010), equivalent to the solution of seismic rays in 2-D problems. Imposing the rupture velocity and shear stress on the rupture plane in advance, the self-similar crack model has only three free parameters, which are the time and 2-D location of the nucleation on the fault. For simplicity, we here set the rupture velocity proportional to the shear wave velocity in the rock (Heimann 2010).

The distribution of slip during rupture is calculated from the instantaneous size and shape of the already broken segments, which is defined by the position of the rupture front. We implement a numerical 3-D boundary element method (BEM), prescribe the stress drop $(\Delta \sigma)$ and invert for dislocation $(\Delta u)$. Since inertia effects on slip are neglected, and only the time-independent effect of friction is considered, the dynamic slip distribution is approximative. The BEM is fast and flexible to consider a wide range of shapes of the 3-D rupture.

Fig. 2 illustrates the concept for a rectangular rupture plane with vertical width $W$ and length $L$, assuming a constant stress drop $\Delta \sigma$ on the plane and a zero stress drop behind the margins of the 
plane. We use the analytical solutions of a circular and an infinite long Griffith crack (e.g. Pollard \& Segall 1987) to illustrate the slip distributions on the $x_{1}$ axis in different stages of the rupture. The rupture starts at a point located at half the fault width. It is growing in the first phase in a self-similar manner with a circular rupture front at steadily increasing distance to the nucleation point in the centre. The slip in the circular growing phase is of elliptical shape with its maximum at the nucleation point (Fig. 2b). The slip rate is non-zero everywhere but largest a close distance behind the rupture front (Fig. 2b). As soon as the rupture front hits the upper and lower margin of the fault, it propagates mostly horizontal in $x_{1}$ direction (Fig. 2a). In this bi- and uni-lateral propagation phase the crack opening is approximated by the solution of a 2D Griffith crack which is infinite in $x_{1}$ direction. Note that the maximum slip of a Griffith crack is slightly larger than the maximal slip of a circular crack, which is not considered in this example for illustration. Where the rupture front has reached its full vertical length $(W)$ the slip does not increase with further rupture growth in $x_{1}$ direction. At this stage, the slip rate is still largest at the front of the ongoing rupture, but ceases to zero behind the front where the crack has touched the upper and lower margin of the rupture plane (Fig. 2b). In other words, a slip pulse rupture mode develops at the transition from circular to unilateral growth, without imposing any friction or other constraints. The rise time of the slip is controlled by a combination of the rupture velocity and the geometrical shape of the rupture front. Although the illustration is approximative, the example demonstrates the principle concept. The numerical implementation considers the finiteness of the plane and arbitrary rupture fronts. The following two subsections describe the details of implementation (see also flowchart in Supporting Information Fig. S1).

\subsection{Rupture front simulation}

The analogy of rupture processes to wave propagation is motivated by studies of rupture plane morphology, showing that curved plumose and conchoidal lines are typically orthogonal to each other (e.g. DeGraff \& Aydin 1987; Helgeson \& Aydin 1991; Kulander \& Dean 1995; Weinberger 1999). Observation on rupture propagation and arrest on cracks, produced in plexiglas (Rummel 1987), confirm the relation of conchoidal lines representing snapshots of rupture fronts and the orthogonal plumose lines, indicating direction of rupture propagation. Detailed video analyses of the rupture development of mode I desiccation cracks in the laboratory, together with in situ measurements of elastic properties of the probes, could verify that the rupture front is related to a spatially variable rupture velocity on the rupture surface (Müller \& Dahm 2000). Therefore, Müller \& Dahm (2000) suggested to apply 2-D ray tracing methods to approximate the rupture front development in isotropic media with smoothly varying rupture velocity. The authors also pointed to important differences between seismic ray theory and rupture front development, as rupture propagation does not follow from first principles as an equation of motion. While wave velocities are material properties, the rupture velocities depend on material properties and the state of stress, pore pressure and the presence of fluids. Seismic wave and rupture fronts may both interfere and interact, but wave fronts never join as rupture fronts may do. If the strength contrast is large, the rupture front may even become discontinuous. The analogy of rupture and wave fronts is therefore only approximate in media with small strength differences, and may occasionally be even wrong. On the other hand, the analogy is suited for the purpose of defining a theoretical rupture model resembling key features of a physical rupture. It can be of benefit for efficient inversion strategies obeying only few parameters.

In order to keep the calculation of rupture fronts simple, we assume that the rupture occurs on a single plane. The orientation and size of this plane can be selected. The rupture velocity is a function of coordinates of the plane, that is, $v_{\mathrm{r}}=v_{\mathrm{r}}\left(\xi_{1}, \xi_{2}\right)$. For the sake of simplicity, we assume in the present study that the rupture velocity scales linearly with the shear wave velocity in the medium, where the scaling factor is taken as free parameter. The point of rupture nucleation is at $(0,0)$. Then, the traveltime function $T=$ $T\left(\xi_{1}, \xi_{2}\right)$ is provided by the Eikonal equation in 2-D,

$\left(\frac{\partial T}{\partial \xi_{1}}\right)^{2}+\left(\frac{\partial T}{\partial \xi_{2}}\right)^{2}=\frac{1}{v_{\mathrm{r}}^{2}}$.

The approach has been tested in a kinematic inversion procedure by Heimann (2010) using the fast marching level set method of Sethian (1996) to solve the Eikonal equation. Here, we reimplemented the algorithm in the $C$ programming language and with bindings for Python. For reusability, we integrated it as an independent module into the open-source seismology toolbox Pyrocko (Heimann et al. 2017) ${ }^{1}$. The algorithm is numerically very efficient and stable. Computations are carried out on a rectangular grid, where grid spacing $\Delta d$ in all dimensions is equal. A first-order finite difference scheme is sufficient in our application. Maximum errors in the calculated rupture front arrival times are on the order of $\Delta d / v_{\mathrm{r}}$, so we can choose the grid spacing fine enough for any desired accuracy. The implemented tool was verified using analytical solutions and by comparison to ray tracing routine Cake in Pyrocko.

\subsection{Calculation of the slip distribution}

The slip is calculated sequentially using a quasi-static crack approach. In order to keep the calculation simple, we replace the physical rupture plane by a fictive planar, infinite plane. After eq. (1) has been solved for a given nucleation point, the snapshots of rupture fronts are available to define time-dependent fracture shapes (e.g. Fig. 2a). The stress drop $\Delta \sigma$ realized during rupture depends mainly on the available shear and normal stress on the fictitious rupture plane and the cohesion of friction. We assume that $\Delta \sigma$ is a fraction of the resolved shear stress on the true rupture plane with given orientation and depth. In order to keep the number of free parameter small, we suggest for future applications to estimate the shear stress from a combination of the world stress map model (Heidbach et al. 2018) with a simple mantle rheology, and keep the scaling factor between stress drop and shear stress as free variable. Known scaling laws between magnitude and stress drop, as given by Kanamori \& Anderson (1975) and Kanamori (1994), are also used to estimate the stress drop. However, at a later stage of the implementation, or if better stress models are available, the stress drop function can be adapted by users choice. For instance, a seismicity model may be easily incorporated into the stress drop model to account for the stress release during previous major earthquakes or a coupling model to account for creeping segments on a plate boundary (e.g. Kaneko et al. 2010) or a rheologic model of the lithosphere. Such different models can be combined into a comprehensive stress drop model.

We employ a boundary element method (BEM) to calculate the slip distribution during rupture. The rupture plane is gridded

\footnotetext{
${ }^{1}$ Pyrocko module pyrocko.eikonal_ext
} 
into rectangular boundary elements (Fig. 2a). Boundary values (b), the stress drop components in $\xi_{1}, \xi_{2}$ and optional $\xi_{3}$ directions (strike-parallel, dip-parallel and plane-normal), are allocated to the midpoints of the boundary elements. The dislocation vector $\Delta u$ (slip) has three components in $\xi_{1}, \xi_{2}$ and optional $\xi_{3}$ direction (in-plane tearing, shearing and opening, respectively). Any dislocation occurring at one boundary element of the plane generates a stress drop contribution at all other boundary elements and vice versa.

Influence or Green's functions $\mathbf{g}$ are calculated between each of the boundary elements and for all possible directions and stress drop-dislocation pairs. They need to be calculated only once, when the problem is set up. The Green's functions describe the sensitivity to generate a stress drop at the midpoint of one boundary element in response to a dislocation at any other boundary element. So far, we use Green's functions for displacements and their spatial derivatives based on closed analytical expressions for dislocations on a rectangular elementary fault within a homogeneous half-space (Okada 1992). The Green's functions implemented so far do not contain elastodynamic terms. Therefore, the derived rupture scenarios are approximate and cannot be used to simulate the rupture-wave interaction. Additionally, we so far do not consider BEM Green's functions of layered media, although this could be implemented in a future release of the software.

For illustration, we map the 2-D matrix problem for the two spatial components into a 1-D vector equation (Fig. 3):

$$
\left[\begin{array}{c}
b_{1} \\
b_{2} \\
\vdots \\
b_{K}
\end{array}\right]=\left[\begin{array}{cccc}
g_{11} & g_{12} & \ldots & g_{1 K} \\
g_{21} & g_{22} & \ldots & g_{2 K} \\
\vdots & \vdots & \ddots & \vdots \\
g_{K 1} & g_{K 2} & \ldots & g_{K K}
\end{array}\right]\left[\begin{array}{c}
\Delta u_{1} \\
\Delta u_{2} \\
\vdots \\
\Delta u_{K}
\end{array}\right],
$$

where unknowns $\left(\Delta u_{j}\right)$, boundary values $\left(b_{i}\right)$ and Green's functions $g_{i j}$ are only associated by indices and without spatial dependences. Note that $g_{i i} \neq 0$ (no summation convention here). $K$ is the number of individual stress drop or dislocation components (number of boundary elements times number of directions). We use a linear least-squares inversion to obtain the dislocation response fulfilling the prescribed boundary values (Menke 1989):

$\Delta \mathbf{u}^{\text {est }}=\left[\mathbf{g}^{\mathrm{T}} \mathbf{g}\right]^{-1} \mathbf{g}^{\mathrm{T}} \mathbf{b}$.

Neither damping nor weighting is applied.

To model the dislocation field during the development of the earthquake rupture, all elements enclosed by the rupture front are determined for each increment of rupture time. They are labelled as active elements. A subset of equations from the pre-set eq. (2) is extracted for the active elements and is used in the dislocation inversion (3). Thus, for each time increment a quasi-static dislocation snapshot is obtained. A series of these snapshots between the start and stop of the rupture samples the dislocation at each grid point as a function of time.

The BEM method is implemented as a tool in the Pyrocko Pythontoolbox for seismology (Heimann et al. 2017). To define boundary elements, a rectangular grid is automatically selected from the geometrical dimensions of the instantaneous rupture area and the smallest $v_{\mathrm{r}}$. The grid size can be adjusted, but is usually much coarser than that used for the computation of the rupture front isochrones. For instance, in the examples below the number of boundary elements can be a factor of 100 smaller than the number of cells to solve the Eikonal equation, to still produce acceptable accurate solutions for the slip distribution. By comparison with analytical crack solutions, Metz (2019) studied the influence of the grid size on the precision of the solutions. Largest deviations occur close to the tip of fracture, where both the slip gradient and slip rate gradient are largest. Sparser grids increase the errors. For most typical applications, the frequencies under study are only a factor 2 or 3 larger than the corner frequency of the rupture. From the extensive numerical tests we concluded that a grid size of $50 \times 20$ is sufficient to model the temporal-spatial evolution of the dislocation on a 50 $\times 20 \mathrm{~km}$ sized fault plane due to a homogeneous stress drop. In terms of computational efficiency, the BEM method implementation has been optimized using CPython extensions and leveraging parallelization. For example, using a fault of $50 \times 20 \mathrm{~km}$ length and a grid size of $50 \times 20$ boundary elements, the calculation of the Green's functions takes $1.8 \mathrm{~s}$ and the following estimation of 16 slip snapshots needs $4.7 \mathrm{~s}$ on a computer with 6 threads. So a complete forward modelling scheme using the named model parameter takes $6.5 \mathrm{~s}$.

The final size of the rupture is determined by the positions where the stress drop or available shear stress becomes zero or negative, as the slip will die out within a short distance after entering such layers. Fig. 4 illustrates the concept. In a forward modelling problem the location, orientation and size of a fault plane is usually pre-defined. For instance, these regions are defined for crustal earthquakes by a superficial layer at the free surface and at depth by lower boundary of the seismogenic depth or by the temperature-controlled brittle-ductile transition. For subduction zone events a zero stress may be assigned to the volumes outside the slab. In practice, the rupture front isochrones are calculated a little into the regions of zero stress (Fig. 4) according to a defined skin thickness. The same skin thickness can be considered to define active elements in the BEM calculation of slip.

In an inversion problem, a key question is where and when to stop the rupture. While the free surface or brittle-ductile boundaries can be easily integrated in a pre-defined, rheological stress model, the lateral extent of the rupture within the seismogenic zone is constrained by the observed seismic moment $M_{0}$ of the earthquake. Here, a specific feature of the self-similar model is employed. While the time-development of rupture and slip-rate (the directivity effects) will depend on the selected nucleation point (e.g. Fig. 4), which is unknown in the inversion problem, the final slip distribution after the arrest of the rupture is independent on where the rupture nucleated. In a first exploratory run we consider rupture growth directly at the centroid location of the moment tensor solution. The calculated seismic moment steadily increases with each step-wise expansion of the rupture front. The calculation is then stopped at the position of the rupture front where the difference between calculated moment and the observed $M_{0}$ is minimal. The geometry of this particular solution explains the low-frequency radiation of observed waves and has the same numerical centroid location as the observed earthquake assuming a well-defined stress drop field (Fig. 4). Note that a small shift between numerical and observed centroid maybe considered at this stage. After the geometry of the rupture plane has been defined by this first calculation, all other possible scenarios of different hypocentres can be tested to explain the observed directivity effects by matching the observed final slip distribution (seismic moment and centroid location). Fig. 4 also illustrates that small-scale heterogeneities in rupture velocity and stress drop (barriers and asperities) can be additionally considered in the modelling geometry. 
(a) time $t_{1}$

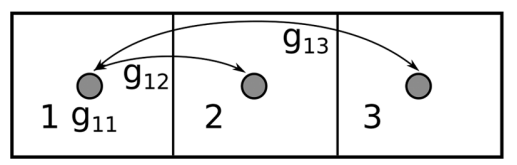

(b) time $t_{2}$

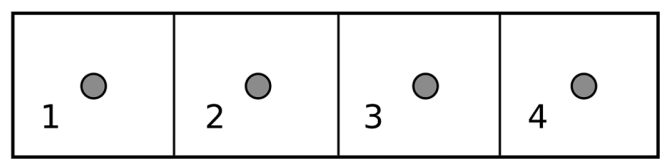

Figure 3. Illustration of the time dependent slip calculation of our model. For a time $t_{1}$ the rupture front encloses the centre points of three boundary elements. The pre-calculated Green's functions ( $g i j)$ are then used to estimate the traction based on the slip or invert the slip from known traction boundary values. For a later time $t_{2}$ the rupture front passed also the centre of boundary element 4 . Thus, the described procedure is repeated including all four boundary elements and new slip or traction distributions are obtained.

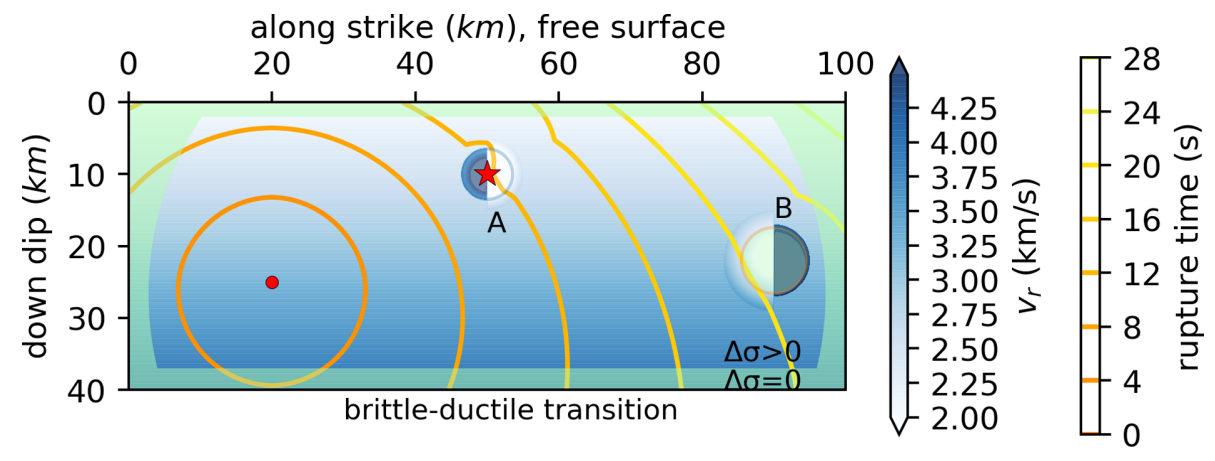

Figure 4. Setup of a fault rupture model. Given is the strike, dip and centroid location (star) of the fault. The rupture velocity (blue grid image, velocity increases with depth) is defined as a fraction of the shear wave velocity structure in the region. A background stress drop model is fixed before modelling, where the regions above $2 \mathrm{~km}$ below surface and below the brittle-ductile transition in $37 \mathrm{~km}$ depth are tapered to zero stress drop, $\Delta \sigma=0$ (green clipped path). Two circular heterogeneities $(\mathrm{A}=$ asperity, $\mathrm{B}=$ barrier) are included as examples (colours indicate increase and decrease of rupture velocity, see Section 3.3. for more explanation). The nucleation point used for computation of rupture front isochrones (coloured contour lines) is given by the red circle.

\section{APPLiCATIONS AND CASE STUDiES}

We demonstrate the model with two case studies of fault settings: (1) thrust faulting along an interplate subduction zone interface, and (2) the strike-slip rupture on an intracontinental, crustal subvertical fault. While the impact of the free surface, vertical and lateral variation of the rupture velocity, and stress heterogeneity on slip rate and pulse duration are illustrated, the examples demonstrate the flexibility and computational efficiency of the approach.

\subsection{Subduction zone interplate earthquakes}

We use the $M_{\mathrm{w}} 8.32015$ Illapel, Chile, earthquake as an example of a shallow dipping earthquake rupture. In such a setting, the rupture velocity typically increases in downdip direction from very small values of less than $2 \mathrm{~km} \mathrm{~s}^{-1}$ at the tie of the subducting plate to more than $4.5 \mathrm{~km} \mathrm{~s}^{-1}$ at the lower end of the seismogenic zone. The Illapel earthquake has been studied in several papers (e.g. Fuentes et al. 2016; Melgar et al. 2016; Okuwaki et al. 2016; Ruiz et al. 2016; Tilmann et al. 2016; Ye et al. 2016; Hayes 2017; Herman et al. 2017; Meng et al. 2018). Although the high-frequency wave radiation of the Illapel 2015 earthquake indicates a complex rupture with the involvement of multiple asperities and complex rupture patterns along both dip and strike directions (e.g. Okuwaki et al. 2016; Ruiz et al. 2016; Tilmann et al. 2016; Meng et al. 2018), the low-frequency radiation is overall simpler. We basically refer to parameters reported in Tilmann et al. (2016), a study where continuous GNSS, broad-band seismological, teleseismic arrays and regional accelerometer data have been combined for a joint kinematic source inversion.

The megathrust earthquake ruptured a $220 \mathrm{~km}$ long and about $145 \mathrm{~km}$ wide segment of the interface between the Nazca and South
America plate. The rupture nucleated downdip in a depth of about $40 \mathrm{~km}$ (Table 1).

The rupture velocity is $1.6 \mathrm{~km} \mathrm{~s}^{-1}$ in the shallow segments and increases downdip up to $2.2 \mathrm{~km} \mathrm{~s}^{-1}$ (see Melgar et al. 2016; Tilmann et al. 2016; Ye et al. 2016). If we base $v_{\mathrm{r}}$ on a shear wave velocity model combining CRUST2.0 (Bassin et al. 2000), AK135 (Kennett et al. 1995) as used by Cesca et al. (2016) with refined wave velocities and densities based on Contreras-Reyes et al. (2017) and Maksymowicz et al. (2015), a scaling factor of 0.6 yields a good fit to observed velocities. However, we implement an equivalent, smoothed gradient model for the rupture velocity along the slab interface, instead of first-order discontinuities as described in CRUST2.0. Uniform boundary tractions are prescribed at the fault interface, with a stress drop of $0.8 \mathrm{MPa}$ (compare to Kanamori 1994). The stress drop is estimated from the background tectonic stress as, for example, given by Wortel \& Cloetingh (1985). The tectonic stress tensor is rotated to obtain the shear stress on the fault plane (here 1.3 MPa). It consists of the stress drop during the earthquake and the remaining frictional strength. Using the stress drop of $0.8 \mathrm{MPa}$, which yield a good fit of the slip distribution, we estimate a frictional strength of about $0.5 \mathrm{MPa}$. The rake angle of $\sim 80^{\circ}-90^{\circ}$ (e.g. Tilmann et al. 2016) is retrieved from the projection of maximal shear stress in the rupture plane and is in agreement with the direction of the maximum horizontal stress (Heidbach et al. 2018). Only mode II and III rupture and no opening is assumed. Furthermore, shear stress is tapered to zero between $5 \mathrm{~km}$ depth and the surface, where unconsolidated sediments near the trench are present (Maksymowicz et al. 2015; Contreras-Reyes et al. 2017).

Fig. 5 shows simulation results in comparison to Tilmann et al. (2016). The centroid location and lateral extend of the rupture plane have been fixed following the procedure described in Fig. 4. The final static slip distribution shows a maximum slip of 5-5.5 $\mathrm{m}$ in the centre of the rupture along strike and in the upper half of the 
Table 1. Pre-defined parameter used for the $M_{\mathrm{w}} 8.32015$ Illapel earthquake. The coordinates of the anchor of the fault with normal vector $\mathbf{n}$ are defined at the surface in its midpoint. $l$ and $w$ give length along $x$ and width along $y$ of the plane; $z$ refers to true depth. If more than one stress model is defined, the values overwrite the stress from the upper line. The CRUST2.0 model refers to the nomenclature given in Bassin et al. (2000). Earthquake parameters were defined with reference to USGS (https://earthquake.usgs.gov/earthquakes/eventpage/us20003k7a), Cesca et al. (2016), Fuentes et al. (2016), Melgar et al. (2016), Tilmann et al. (2016), Hayes (2017), and Herman et al. (2017).

\begin{tabular}{|c|c|c|}
\hline \multicolumn{3}{|l|}{ Fault geometry and orientation } \\
\hline lat/lon/strike/dip & length/width & $\mathbf{n}[$ ned $]$ \\
\hline $\begin{array}{l}-31.0^{\circ} /-72.6^{\circ} / 5^{\circ} / 20^{\circ} \\
\text { Nucleation }\end{array}$ & $300 \mathrm{~km} / 150 \mathrm{~km}$ & $\begin{array}{l}{[-0.03,0.341,-0.94]} \\
\text { Initial centroid }\end{array}$ \\
\hline lat/lon/z/x/y & $M_{0}$ & lat $/ \operatorname{lon} / z / x / y$ \\
\hline $\begin{array}{l}-31.55^{\circ} /-71.55^{\circ} / \\
38.0 \mathrm{~km} /-52.7 \mathrm{~km} / 111.2 \mathrm{~km} \\
\text { Stress model }\end{array}$ & $3.5 \times 10^{21} \mathrm{Nm}$ & $\begin{array}{l}-31.13^{\circ} /-72.09^{\circ} / \\
18.1 \mathrm{~km} /-10.3 \mathrm{~km} / 52.8 \mathrm{~km}\end{array}$ \\
\hline $\mid\left[t_{x}, t_{y}, t_{z}|=| \mathbf{t} \mid\right.$ & range & rake $[$ ned $]$ \\
\hline $\begin{array}{l}|[0.0,0.0,0.0]|=0.0 \mathrm{MPa} \\
|[-0.04,0.799,0.0]|=0.8 \mathrm{MPa} \\
\text { Velocity model }\end{array}$ & $\begin{array}{l}0 \mathrm{~km}<z \leq 5 \mathrm{~km} \\
5 \mathrm{~km}<z\end{array}$ & $\begin{array}{l}93^{\circ},[0.03,-0.939,-0.342] \\
93^{\circ},[0.03,-0.939,-0.342] \\
\text { Boundary elements }\end{array}$ \\
\hline CRUST2.0 ID & $\gamma$ & $n_{x} / n_{y}$ \\
\hline $\mathrm{R} 2$ & 0.6 & $35 / 20$ \\
\hline
\end{tabular}

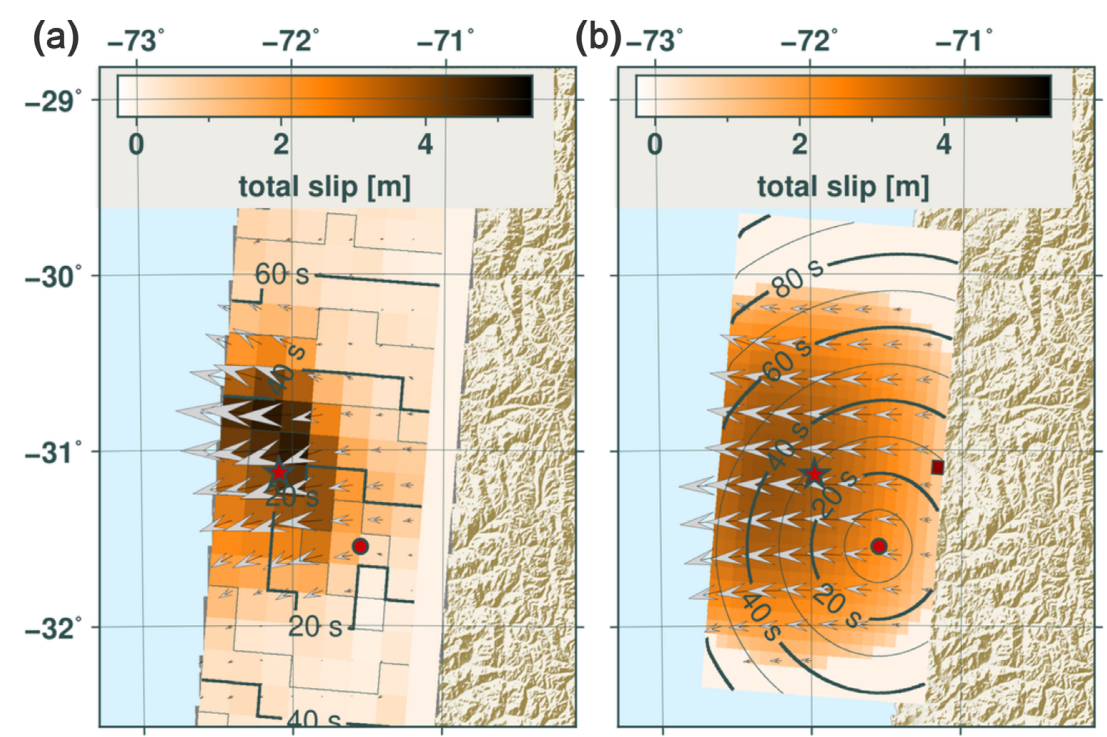

Figure 5. Comparison of the final static slip results from Tilmann et al. (2016) (a) (finite fault modelling using GPS) to our results (b) for the 2015 Illapel earthquake. Slip is colour-coded and contour lines indicate the rupture front arrival time. Arrows scaled by the total slip show both slip direction. The red point highlights the nucleation point, the red star the centroid given by GCMT (a) and using our self-similar rupture model (b). The red square in (b) indicates one boundary element, whose moment rate function is shown in Fig. 6(c). The main asperity is located in both cases on the upper segment of the fault plane with a maximum slip of 5-5.5 m. Also the areas of larger slip match well. Tilmann et al. (2016) derive a more pronounced asperity though. Their rupture front velocities are in the same range as our results obtained with the Eikonal equation.

fault up to the trench, corresponding to a depth range of $15-20 \mathrm{~km}$. The estimated length, width and slip distribution is consistent with the results of Tilmann et al. (2016) and other studies. The modelled seismic moment of $3.284 \times 10^{21} \mathrm{Nm}$ is very similar to the $M_{0}=$ $3.488 \times 10^{21} \mathrm{Nm}$ estimated by Tilmann et al. (2016). The small misfit indicates a good accuracy considering the sparse boundary element grid and time sampling. High slip patches on a rupture plane are often interpreted as regions where elevated stress levels existed before (e.g. asperities and barriers) and led to higher slip during rupture. However, in our modelling a homogeneous stress drop model has been used, and the concentration of slip in the upper half of the centre of the fault is controlled by the shape of the fault and the free surface.

Fig. 5 also indicates the estimated direction of slip. Smooth variations of slip directions are found in the outer region of the fault, very similar to the slip variations resolved in the kinematic inversion by Tilmann et al. (2016). The mean slip direction is in agreement with the direction of the maximal shear stress resolved on the given plane. This is not unexpected, but demonstrates that starting from plate convergence models and the orientation of the subducting 
slab can lead to a reasonable modelling of the static features of the rupture including variability of slip.

The rupture nucleation has been fixed to the hypocentre reported in Melgar et al. (2016) and Tilmann et al. (2016). A fast propagation of rupture fronts along the deeper tip of the rupture front and an upward bending of fronts towards shallower levels is indicated by the distance and curvature of the isochrones (Fig. 5b). A similar pattern, but poorly sampled, is indicated in the kinematic inversion of observed data (Fig. 5a).

It is interesting to look to predicted directivity effects and the point source equivalent STF. As we do not forward-propagate wavefields in this study, we compare moment rate functions in single points on the rupture plane, or sum them up to represent farfield STF in specific directions. For instance, the STF developed in Brune's model is calculated for a ray perpendicular to the fault. In our case, we sum 'in-phase' over all moment rate functions (MRFs) at all boundary elements to obtain the STF equivalent to the orthogonal ray. The self-similar rupture model shows a triangular shaped moment rate function, similar to the one observed in Okuwaki et al. (2016) and Tilmann et al. (2016), but with a slightly larger peak of $\sim 1 \times 10^{20} \mathrm{Nm} \mathrm{s}^{-1}$ (Fig. 6a). The peak of the STF retrieved by Tilmann et al. (2016) arrives about $5 \mathrm{~s}$ earlier and shows a slightly longer tail. A possible explanation can be a smaller stress drop at the northern end of the ruptured segment, so that slip on this segment would become smaller and the rupture plane would be extended in our modelling to fit $M_{0}$. For instance, Metois et al. (2012) developed an interseismic coupling model for the central Chilean subduction zone indicating strong segmentation along the plate interface. However, the asymmetry of the STF of the 2015 Illapel earthquake is not confirmed in every study. For instance Okuwaki et al. (2016) derives a symmetric STF very similar to our solution (Fig. 6a). Therefore, we do not investigate this possibility further. The far-field STF in Fig. 6(a) is the superposition of the MRFs at single boundary elements. In Figs 6(b) and (c), we plot the localized MRFs at the centroid location and at a deeper boundary element on the fault with similar rupture arrival time. The MRF at the centroid shows a slip pulse with a second peak $50 \mathrm{~s}$ after origin time, and a strong decay after the peak. The second peak is caused by the rupture arrival at the surface leading to larger slips and rerupturing at the depth of the centroid. The MRF at a deeper patch on the fault is shorter in its duration and shows a stronger decay after the peak (Fig. 6c). Due to the large depth hardly any re-rupturing is recognized. The shorter duration and faster decay are explained by the large distance to the free surface and a smaller rupture front curvature at larger depth compared to the centroid location.

It is noteworthy that all the details on the MRF and STF are results from the simulation by itself, without constraining any parameter as rise time or friction. They are only controlled by the instantaneous shape of the rupture front and the interaction of boundary elements to maintain the balance of force equilibrium.

\subsection{Subvertical plane intraplate earthquake}

Intraplate earthquakes occur in different tectonic settings, as normal dipping faults at graben systems, low angle continental thrust faults, or on subvertical strike-slip faults where transformational strain accumulates and strike-slip earthquakes occur. We use a subvertical fault as a case study. The ruptures are often confined to a vertical width of 10 or $15 \mathrm{~km}$, and the length of the rupture may have several tens to several hundreds of kilometres if the earthquakes have magnitudes above $M_{\mathrm{w}} 7$. Rupture may involve different segments of faults with varying strike and dip. Fault segmentation and fault bending is often observed for intraplate earthquakes (and at subduction zones), and may be recognized by teleseismic data that are sensitive to changes in fault direction (e.g. Shimizu et al. 2020). Often, the stress drop of intraplate earthquakes is in the range of $10 \mathrm{MPa}$ and large compared to interplate subduction zone events. Rupture velocity is typically small if the rupture is confined to shallow crustal depth, but some cases of fast rupture velocities above the typical crustal $S$-wave velocity (super-shear velocity) have been reported for strike-slip earthquakes with large extension. We first discuss the rupture of a shallow, medium-size strike-slip earthquake with vertical varying $v_{\mathrm{r}}$ and lateral varying $\Delta \sigma$, and then illustrate the effect of long ruptures which break parts of the upper mantle. The first case is in the style of the $M_{\mathrm{w}} 7.12016$ Kumamoto, Japan, earthquake with a dip of the fault plane of $66^{\circ}$; the second in the style of the $M_{\mathrm{w}} 7.52018$ Palu, Indonesia, event. A final example demonstrates the possibility to simulate small-scale stress and velocity heterogeneities, the so-called asperities and barriers.

The 2016 April $15 M_{\mathrm{w}}$ 7.1 Kumamoto, Japan, earthquake ruptured a 40-55 km long and about 15-25 km wide section of the NNE trending Hinagu and NE trending Futagawa intracrustal fault zone. The study of InSAR and near fault strong motion recordings showed that the earthquake activated at least three fault segments with slightly different strike and dip angles (e.g. Asano \& Iwata 2016; Kato et al. 2016; Kubo et al. 2016; Ozawa et al. 2016; Yarai et al. 2016; Moore et al. 2017). The slip was partitioned between these segments, with a maximum slip of 4-5 $\mathrm{m}$ and surface ruptures up to $2 \mathrm{~m}$ in the central segment (e.g. Kubo et al. 2016). The average stress drop of 4.5 MPa (Oth et al. 2017) accordingly varied with largest values up to $9 \mathrm{MPa}$ at shallow depths on the central segment (Yarai et al. 2016) and about $1 \mathrm{MPa}$ at the other segments and in the lower crust (Moore et al. 2017). The inferred rupture velocity is with $2.4 \mathrm{~km} \mathrm{~s}^{-1}$ relatively small (Asano \& Iwata 2016; Yarai et al. 2016). Other parameters of the modelling geometry of the Kumamoto earthquake are provided in Table 2.

We use the CRUST2.0 shear wave velocity model at Kumamoto to define $v_{\mathrm{r}}$ with a factor of $0.6 v_{\mathrm{S}}$ (Fig. 7). The seismogenic zone is defined from 0 to $18 \mathrm{~km}$ depth. Below the seismogenic zone, the stress drop is set to $\Delta \sigma=0$. However, the fault model is reaching a depth of $22.8 \mathrm{~km}$ to investigate the slip in the underlying zone of zero stress. A free surface boundary condition has been assumed. We define three segments in the seismogenic zone from -25 to $-10 \mathrm{~km},-10$ to $0 \mathrm{~km}$ and 0 to $25 \mathrm{~km}$ length, respectively, with a stress drop of $\Delta \sigma=7.5 \mathrm{MPa}$ in the central segment and $2 \mathrm{MPa}$ in the northern and southern segments (Fig. 7). The stress drop variations are quite strong, and are regarded as demonstration. They can be caused be different orientation of and/or different frictional strength on the fault segments. The nucleation point is selected at the southern upper end of the rupture plane to simulate uni-lateral rupture mode as observed for the Kumamoto earthquake. The fault segments differ in strike. We approximate these strike changes by using slightly different rakes on the centre and on both marginal segments (Table 2). Thereby the effect of a changed segment orientation in the background stress field can be assessed.

Fig. 7 shows the used velocity and stress model together with rupture front isochrones. The rupture fronts are curved in the upper crust and lag behind an almost planar rupture front propagating in the lower crust. The effect is similar to what is known from diving and refracted waves in wave-propagation problems. For the Kumamoto earthquake, the refracted rupture front is in its initial phase and does not reach the surface. However, as we 
(a)
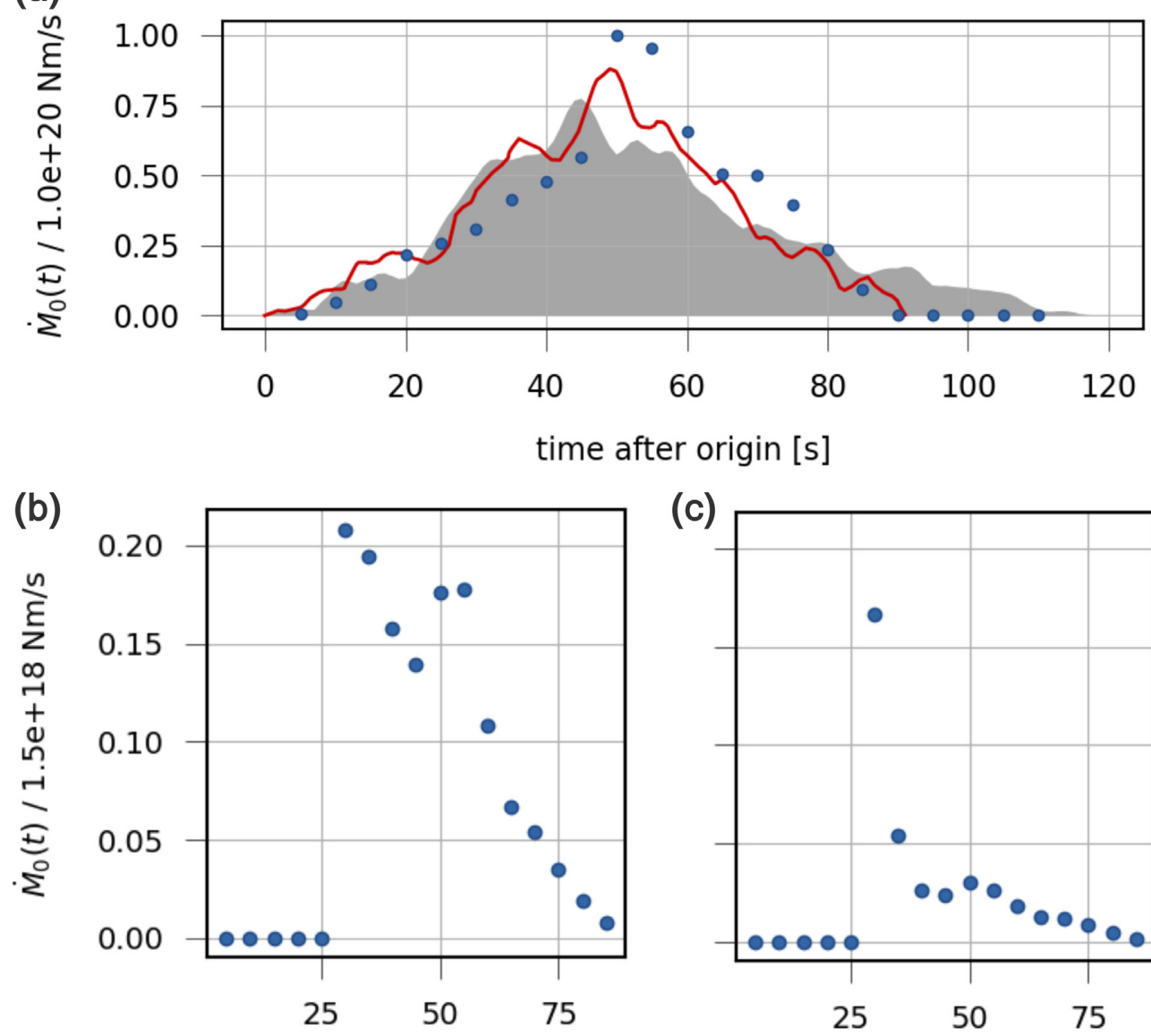

(c)

time after origin [s]

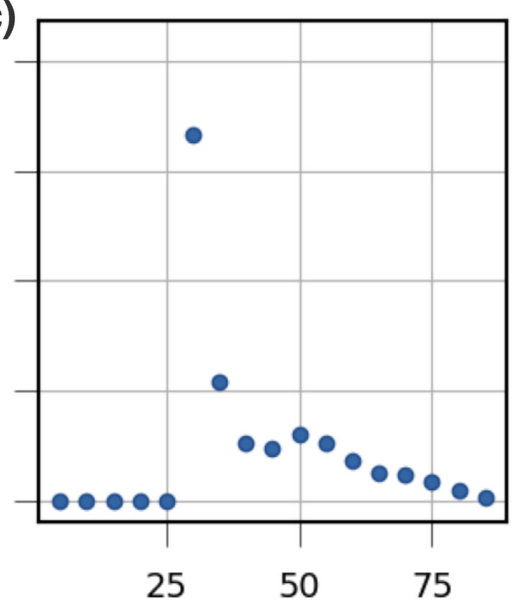

time after origin [s]

Figure 6. (a) Modelled source time function (STF) for the 2015 Illapel earthquake from Tilmann et al. (2016) (shaded area), from Okuwaki et al. (2016) (red curve) and based on our quasi-static rupture model (blue dots). The plot is normalized to the maximum modelled moment rate. (b and c) Normalized moment rate functions (MRF) for two selected boundary elements at the centroid point (b) and a boundary element at the lower edge of the rupture (c) with similar rupture arrival time (red square in Fig. 5b).

discuss later, for rupture planes of longer length the apparent horizontal rupture velocity measured at the surface may reach values close to lower crust and upper mantle shear wave velocities and can explain the observation of apparent super-shear rupture velocities.

Snapshots of the individual moment-rates of each boundary element are plotted in Fig. 8 for three times at 5, 10 and $15 \mathrm{~s}$. The slip-rate (not plotted) is linearly linked with the moment rate and thus shows the same behaviour. The peak of the rate functions delineate more or less the position of the rupture front. In the first $2.5 \mathrm{~s}$ the rupture propagates in all directions and slip and slip rate continuously increases with spreading rupture front (crack-like growth). After the rupture has broken the full vertical width of the brittle zone at the location of the nucleation point, a transition from crack-like to pulse-like bi- and uni-lateral propagation mode is observed. The transition begins about $5 \mathrm{~s}$ after rupture nucleation. The shape and peak value of the moment-rate pulse do not change during the unilateral growth, with the exception when entering and leaving the central segment of high stress drop. Because of the difference in stress drop in the forward- and backward-looking segment of the rupture plane, the self-similar shearing of the fracture is distorted and the slip-rate (or moment-rate) experiences an apparent reflection, as the fault moves at positions behind the rupture front that were previously already at rest (Fig. 8). This apparent back propagation becomes more visible when we plot the colour meshed slip rate as a function of distance and time along a strike-parallel profile at medium fracture depth (Fig. 9). At a distance of $x<25 \mathrm{~km}$, after the fracture front has entered the high stress drop region, the slip rate increases at the fracture front but also behind along the already fractured segment at $x>25 \mathrm{~km}$ where the slip pulse had already healed. The backward spreading slip rate front seems to have the same speed as $v_{\mathrm{r}}$ (Fig. 9) but a much smoother onset. The apparent backpropagation is interesting as it develops without imposing any dynamic friction. Other models have tried to explain a re-rupturing by frictional re-triggering.

Interesting is also to look to patches close to the surface and in the lower crust where we prescribed $\Delta \sigma=0$. The interaction of the crack with the free surface leads to an increase of the slip-rate and moment-rate close to the surface. As a result, also the final slip grows asymmetrically with respect to the depth coordinate. This effect is well known from physical crack models and covered by the BEM modelling. Maybe more unexpected, Fig. 8 also shows that some slip occurs in the lower crust below the brittle zone. This tapering of crack growth into the weak zones of rock that do not carry shear 
Table 2. Pre-defined parameters for the $M_{\mathrm{w}} 7.12016$ Kumamoto earthquake. The coordinates of the anchor of the fault with normal vector $\mathbf{n}$ are defined at the surface in its midpoint. $l$ and $w$ give length along $x$ and width along $y$ of the plane; $z$ refers to true depth. If more than one stress model is defined, the values overwrite the stress from the upper line. The CRUST2.0 model refers to the nomenclature given in Bassin et al. (2000). Earthquake parameters were defined with reference to USGS (https://earthquake.usgs.gov/earthquakes/eventpage/us20005iis), Kubo et al. (2016), Yarai et al. (2016), Asano \& Iwata (2016), Yano \& Matsubara (2016), Yarai et al. (2016), Moore et al. (2017), Oth et al. (2017), AIST (2012), Ozawa et al. (2016), Yagi et al. (2016), Kato et al. (2016) and Lin et al. (2016).

\begin{tabular}{|c|c|c|}
\hline \multicolumn{3}{|l|}{ Fault geometry and orientation } \\
\hline lat/lon/strike/dip & length/width & $\mathbf{n}[$ ned $]$ \\
\hline $\begin{array}{l}32.8^{\circ} / 130.85^{\circ} / 224^{\circ} / 66^{\circ} \\
\text { Nucleation }\end{array}$ & $50 \mathrm{~km} / 25 \mathrm{~km}$ & $\begin{array}{l}{[0.63,-0.66,-0.41]} \\
\text { Initial centroid }\end{array}$ \\
\hline lat/lon/z/x/y & $M_{0}$ & lat/lon/z/x/y \\
\hline $\begin{array}{l}32.75^{\circ} / 130.75^{\circ} / \\
6.4 \mathrm{~km} / 10.5 \mathrm{~km} / 7.1 \mathrm{~km} \\
\text { Stress model }\end{array}$ & $4.5 \times 10^{19} \mathrm{Nm}$ & $\begin{array}{l}32.85^{\circ} / 130.88^{\circ} / \\
4.4 \mathrm{~km} /-5.5 \mathrm{~km} / 4.9 \mathrm{~km}\end{array}$ \\
\hline$\left|\left[t_{x}, t_{y}, t_{z}\right]\right|=|\mathbf{t}|$ & range & rake $[$ ned $]$ \\
\hline $\begin{array}{l}|[-1.76,-0.94,0]|=2 \mathrm{MPa} \\
|[-6.6,-3.53,0]|=7.5 \mathrm{MPa} \\
\text { Velocity model }\end{array}$ & $\begin{array}{l}0 \mathrm{~km}<z \leq 18 \mathrm{~km} \\
-10 \mathrm{~km} \leq x \leq 0 \mathrm{~km}\end{array}$ & $\begin{array}{l}180^{\circ},[0.72,0.69,0.0] \\
-152^{\circ},[0.77,0.48,0.43] \\
\text { Boundary elements }\end{array}$ \\
\hline CRUST2.0 ID & $\gamma$ & $n_{x} / n_{y}$ \\
\hline $\mathrm{J} 1$ & 0.6 & $50 / 30$ \\
\hline
\end{tabular}

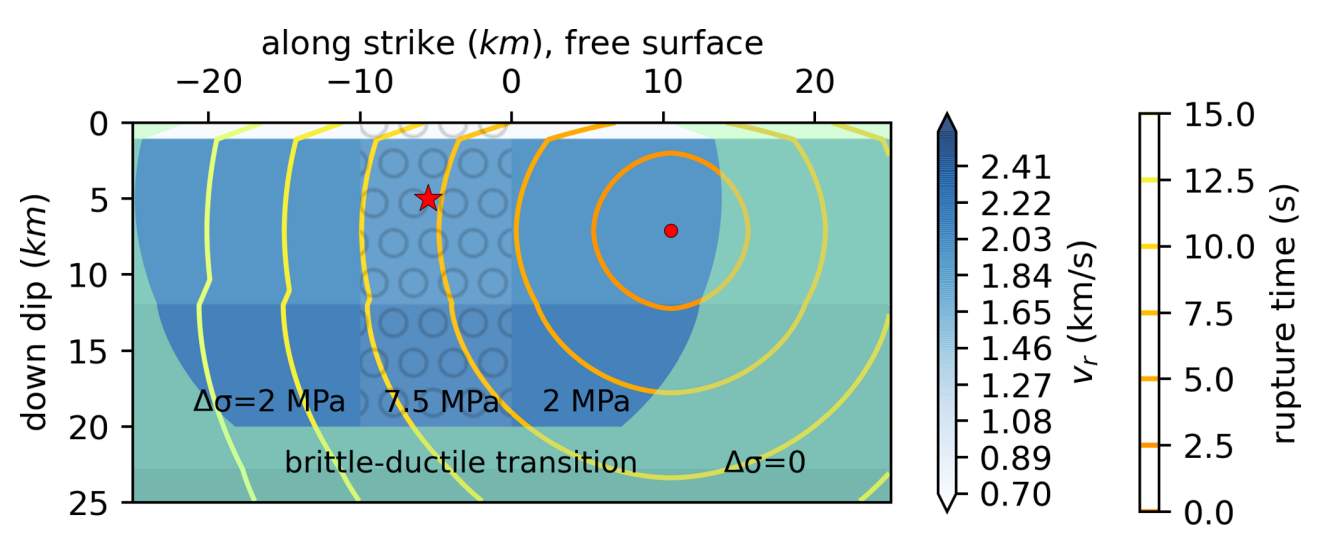

Figure 7. Geometry and model to simulate the rupture of the $M_{\mathrm{W}} 7.12016$ Kumamoto, Japan, earthquake. A rupture plane of $50 \times 25 \mathrm{~km}$ is used. The rupture velocity (blue grid), overlayed by regions of zero stress (green), is retrieved from the layer shear wave velocity model of CRUST2.0 and a factor of $\gamma=0.6$. Rupture front isochrones are plotted for rupture nucleation point (red circle) at the southern upper end of the plane. For the stress model $\Delta \sigma=2 \mathrm{MPa}$ is defined in down dip direction between 0 and $19.7 \mathrm{~km}$. In a northern central segment of the plane of $10 \mathrm{~km}$ length a high stress asperity of $\Delta \sigma=7.5 \mathrm{MPa}$ with slightly different orientation of the maximal shear (Table 2) is assumed (whitened region with circle patter). Along strike, $\Delta \sigma=0$ (green boundary) constrains the area of non-zero slip simulation. It has been defined by simulating a rupture spreading from the centroid point (red star) until $M_{0}$ equals the moment of the point source moment tensor inversion.

stress is partly observed in nature. It is explained in our model by the self-stress created by the shearing of the planes of the fracture (e.g. Dahm 2000).

The parameters in the modelling (Table 2) were selected following the 2016 Kumamoto earthquake. We therefore compare the final slip distribution and the total duration of the rupture modelling directly with results by Kubo et al. (2016). The final slip distribution shows the largest slip in the shallow part of the central fault segment (Fig. 10), similar to observations. Our model slightly overestimates the near surface slip, in comparison to values given in Kubo et al. (2016). This indicates that the shear stress at the fault has been smaller in the uppermost layers close to the surface, a possibility we did not account for in our model. A slight change in slip direction is modelled by varying the direction of prescribed stress drop in the central segment compared to outer segments (Table 2).
We determine the rupture velocity from the linear scaling as $v_{\mathrm{r}}$ $=0.6 v_{\mathrm{s}}$, which leads to velocities between 2.1 and $2.2 \mathrm{~km} \mathrm{~s}^{-1}$. That is, $0.2-0.3 \mathrm{~km} \mathrm{~s}^{-1}$ smaller than proposed by Yarai et al. (2016) and Asano \& Iwata (2016). Therefore, our overall duration of the rupture is with $\sim 18 \mathrm{~s}$ slightly larger than the one found by Kubo et al. (2016).

The $M_{\mathrm{w}} 7.52018$ Palu (Indonesia) earthquake is a left-lateral strike-slip event that ruptured a 150-250 km long and about $30 \mathrm{~km}$ wide segment of the vertical Palu-Koro fault with a modelled maximum slip of 5-8 m (e.g. Fang et al. 2019; Song et al. 2019; Ulrich et al. 2019; Yolsal-Çevikbilen \& Taymaz 2019; Okuwaki et al. 2020). A fast rupture front propagation of 4 to possibly more than $5 \mathrm{~km} \mathrm{~s}^{-1}$ was suggested by waveform modelling and backprojection of teleseismic waveforms (Bao et al. 2019; Fang et al. 2019; Socquet et al. 2019; Ulrich et al. 2019; Yolsal-Çevikbilen \& 

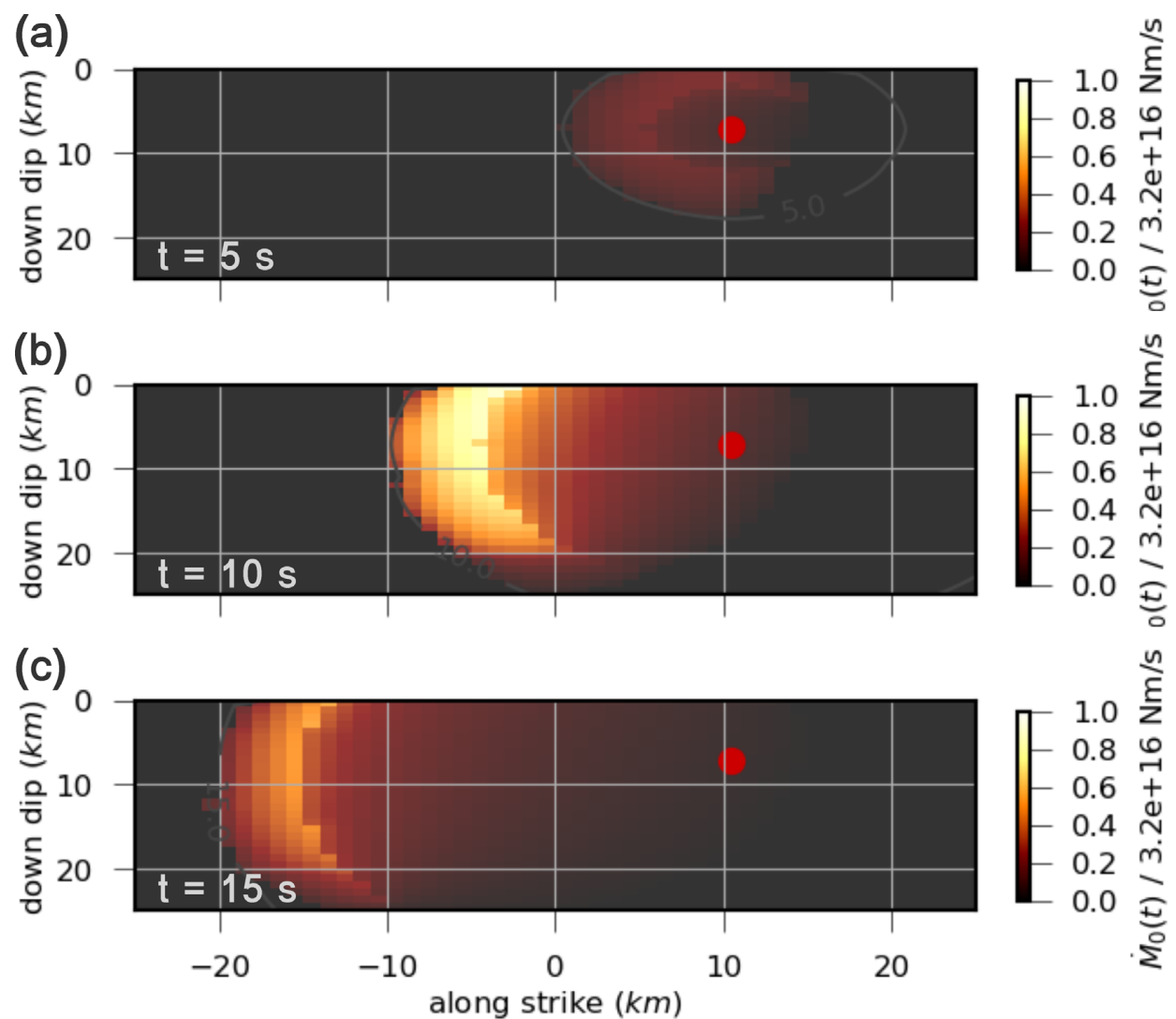

Figure 8. Snapshots of moment rate distributions for three different times: (a) $t=5 \mathrm{~s}$, (b) $t=10 \mathrm{~s}$ and (c) $t=15 \mathrm{~s}$. The red circle indicates the nucleation point. (a) Circular to bilateral rupture growth with major moment release close to the rupture front, with moderate moment rates. (b) Highest moment rates, as the rupture reached the high stress drop segment (compare Table 2). (c) Final stage of rupturing with lower moment rates, as the rupture front has left the high stress drop segment. The zero-stress drop in the lower crust below $18 \mathrm{~km}$ leads to significantly reduced moment rates in this segment.

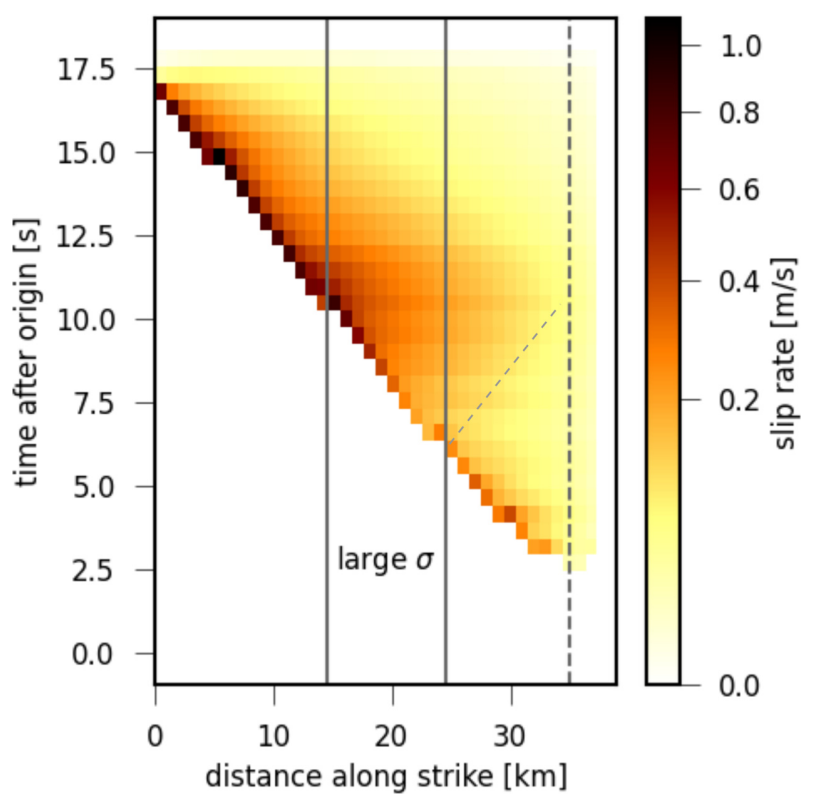

Figure 9. Colour meshed spatiotemporal evolution of the slip rate for the 2016 Kumamoto earthquake model along a profile in $10.3 \mathrm{~km}$ depth along strike from SW to NE. The dashed vertical line indicates the position of the focal point. The segment with high stress drop between 15 and $25 \mathrm{~km}$ is indicated by solid lines. The thin dashed line indicates the slowness of a back-propagating pulse reflected at the high stress segment.
Taymaz 2019; Okuwaki et al. 2020). We adapted the fault model to the geometry of the Palu earthquake (Table 3) to simulate an apparent super-shear rupture by using a conventional scaling factor of $v_{\mathrm{r}} / v_{\mathrm{s}}<1.0$. Shear stress has been prescribed over the uppermost $20 \mathrm{~km}$ of the crust (following Ulrich et al. 2019) with a zero stress layer beneath representing the ductile part of lower crust. The location and depth of the nucleation point was subsequently varied in our modelling. Snapshots of slip rate and the final slip distribution are shown in the Supporting Information (Figs S2 and S3). We assume an enlarged rupture width of $45 \mathrm{~km}$ to test if rupture front refractions from the upper mantle could lead to apparent super-shear arrivals at the surface.

In Fig. 11, we compare rupture front arrival times at the boundary elements at the surface with the radiation times of high-frequency energy on the fault inferred from the backprojection of teleseismic waveforms by Bao et al. (2019). Similar to Bao et al. (2019) we assume that the location and timing of imaged radiators represent the arrival of the rupture front. The measured radiator times have a large scatter and can on average be explained using $\gamma=v_{\mathrm{r}} / \nu_{\mathrm{s}}=0.95$, independent of the selected depth of the nucleation point between 19 and $28 \mathrm{~km}$. The modelled arrivals times are plotted in a time-reduced scale so that sub-shear propagation $\left(v_{\mathrm{r}}<3.9 \mathrm{~km} \mathrm{~s}^{-1}\right.$, representing the velocity between 21 and $32 \mathrm{~km}$ depth) is indicated by a positive slope while super-shear propagation by a negative slope. In the first $60 \mathrm{~km}$ the slope is negative independent of nucleation depths, while it turns into a positive slope (sub-shear arrivals) between 60 and $100 \mathrm{~km}$ distance. At a distance larger than $100 \mathrm{~km}$ from the nucleation point a shallow nucleation at a depth of $19 \mathrm{~km}$ continues 
(a)

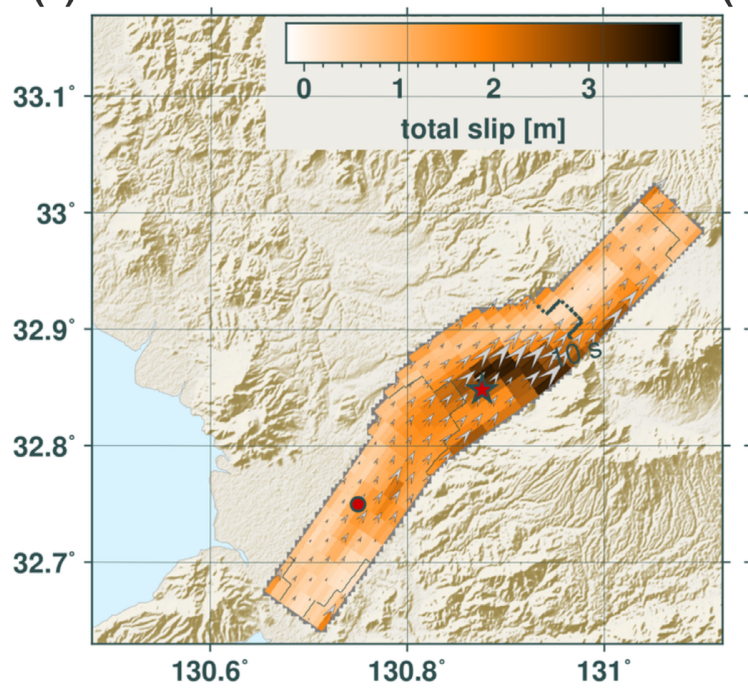

(b)

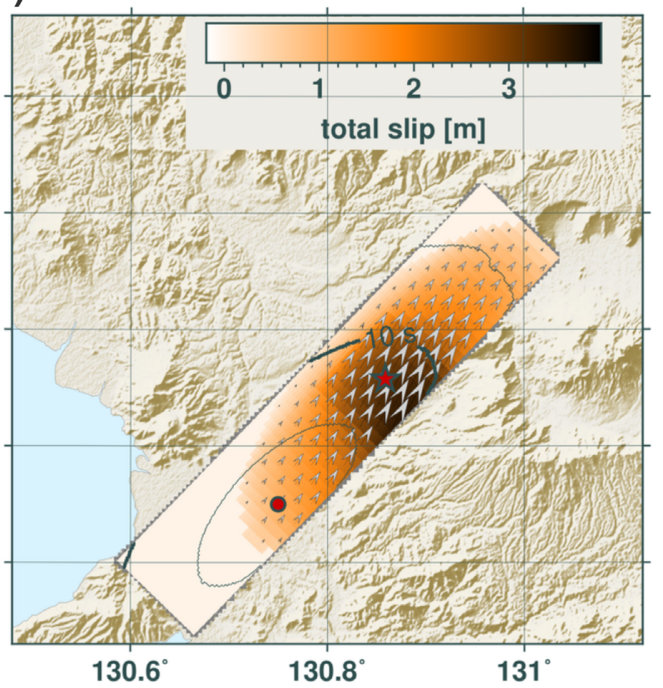

Figure 10. Static slip results from Kubo et al. (2016) using (a) a curved finite fault model and (b) our modelled slip distribution for the 2016 Kumamoto earthquake assuming a heterogeneous stress drop field. The slip is colour-coded and contour lines indicate the rupture front arrival in $s$ after origin time. Arrows show the direction of slip. The nucleation point and centroid locations used in the respective studies are indicated by red circles and stars respectively. The overall slip distribution is similar, but we overestimate both the extension and absolute slip of the main asperity compared to Kubo et al. (2016).

Table 3. Pre-defined parameters for the $M_{\mathrm{w}} 7.52018$ Palu earthquake. The coordinates of the anchor of the fault with normal vector $\mathbf{n}$ are defined at the surface in its midpoint. $l$ and $w$ give length along $x$ and width along $y$ of the plane; $z$ refers to true depth. The CRUST1.0 model refers to the nomenclature given in Laske et al. (2013). Earthquake parameters were defined with reference to USGS (https://earthquake.usgs.gov/earthquakes/eventpag e/us1000h3p4), GMCT, Fang et al. (2019), Bao et al. (2019), Yolsal-Çevikbilen \& Taymaz (2019), Laske et al. (2013), Okuwaki et al. (2020), Ulrich et al. (2019) and Song et al. (2019).

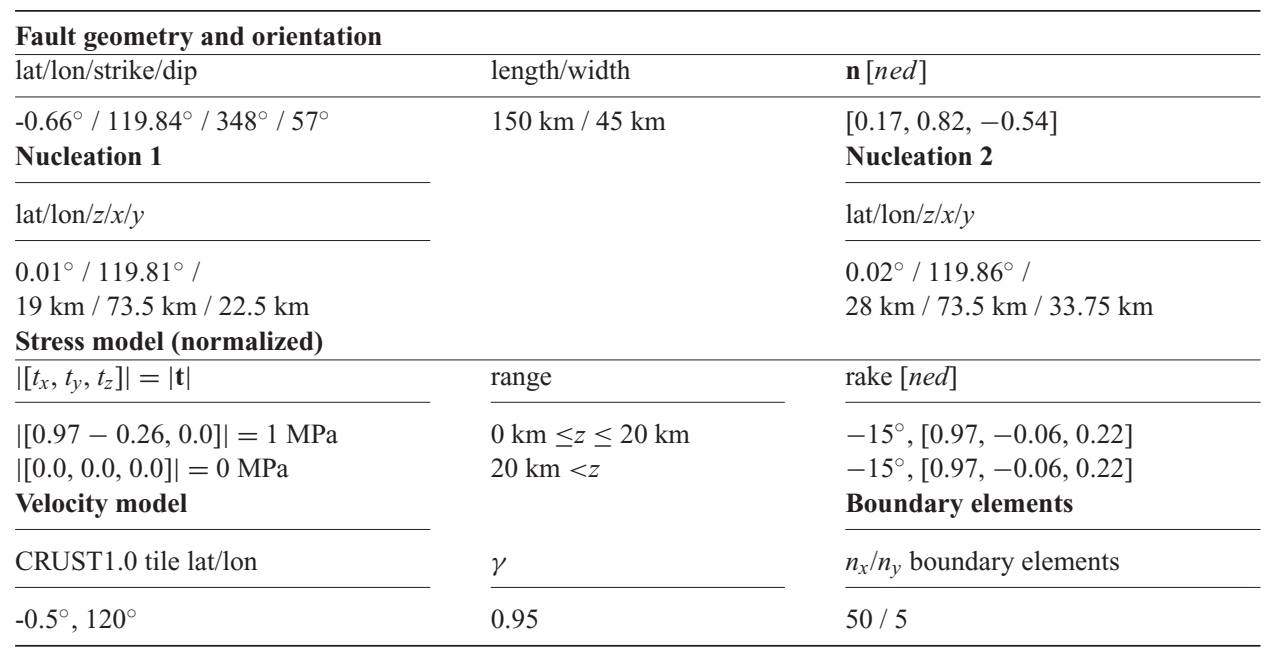

the horizontal propagation with subshear velocities, while the deep nucleation at $28 \mathrm{~km}$ turns again into a negative slope indicating an apparent super-shear lateral propagation. We obtain a horizontal velocity of up to $4.3 \mathrm{~km} \mathrm{~s}^{-1}$ due to the arrival of the refracted rupture front from upper mantle depth. Backpropagation methods as the one used by Bao et al. (2019) have almost no vertical resolution and may falsely interpret the fast lateral propagation as super-shear, while is actually caused by the involvement of deep fault segments in rupturing.

The fast rupture of the 2018 Palu earthquake from north to south was independently deduced from the observation of Rayleigh wave Mach cones under azimuths of $134^{\circ}$ and $220^{\circ}$ (Bao et al. 2019, their Fig. 3). It is therefore interesting to simulate and illustrate the directivity of the apparent STF and of the radiated Rayleigh waves with our rupture model, which are produced without imposing any constraints on the rise time or friction. To calculate direction dependent STF we sum the moment rate function at each boundary element in the lower crust with a systematic delay of $\left(\mathbf{x}_{\mathbf{i}}-\mathbf{x}_{\mathbf{0}}\right) \gamma / v_{S}$ where $\mathbf{x}_{\mathbf{i}}$ and $\mathbf{x}_{\mathbf{0}}$ are the coordinate vectors of the boundary element with index $i$ and at the centroid location, respectively. $\gamma$ is the direction cosine (unit vector) pointing from the centroid to the (far-field) station. We use $\gamma=[ \pm 1,0,0]$, so that the shape of the full-space $S$ wave pulse radiated in or against the direction of rupture is simulated, respectively. The apparent STFs for the two selected directions in Fig. 12(a) show a clear directivity pattern. The station in direction of the rupture have a short pulse, high amplitudes and a relatively short low amplitude tail. The station in opposite direction behind the propagating fracture front shows a long 
(a)
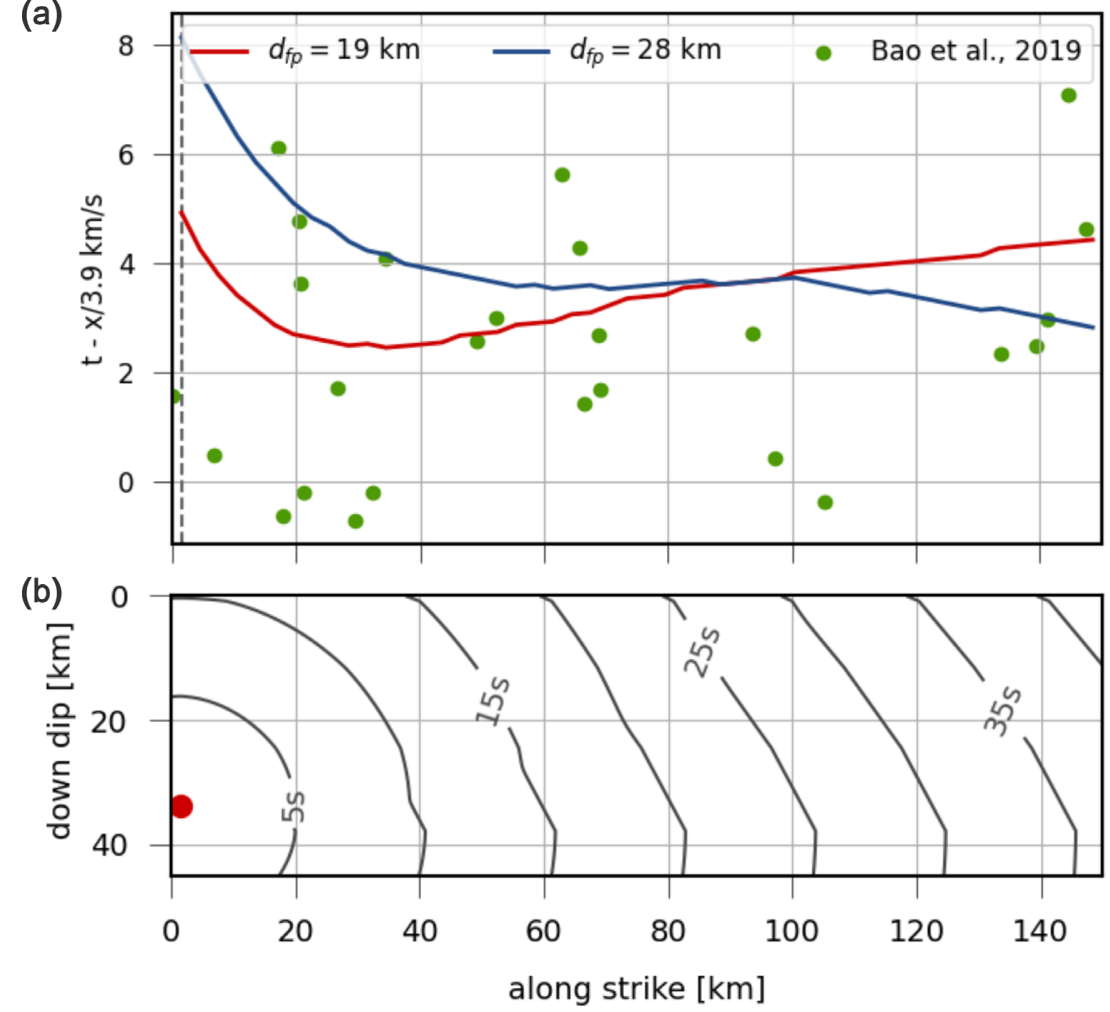

Figure 11. Illustration of the character of rupture fronts and horizontal (apparent lateral) rupture velocities as a function of the depth of the nucleation point $\left(d_{\mathrm{fp}}\right)$. The geometry is adapted to the 2018 Palu earthquake, where the given $x$ coordinates along strike are measured from the rupture plane anchor point at the northern rupture tip towards south. (a) Observed (green circles, from Bao et al. 2019) and modelled rupture front arrivals (lines) at the surface boundary elements for a nucleation depth of $19 \mathrm{~km}$ (red) and $28 \mathrm{~km}$ (blue). Time axis has been reduced using a reduction velocity of $3.9 \mathrm{~km} \mathrm{~s}^{-1}$ (equivalent to rupture front velocity between 21 and $32 \mathrm{~km}$ depth). (b) Example of rupture front isochrones on the rupture plane for a nucleation depth of $28 \mathrm{~km}$.

(a)

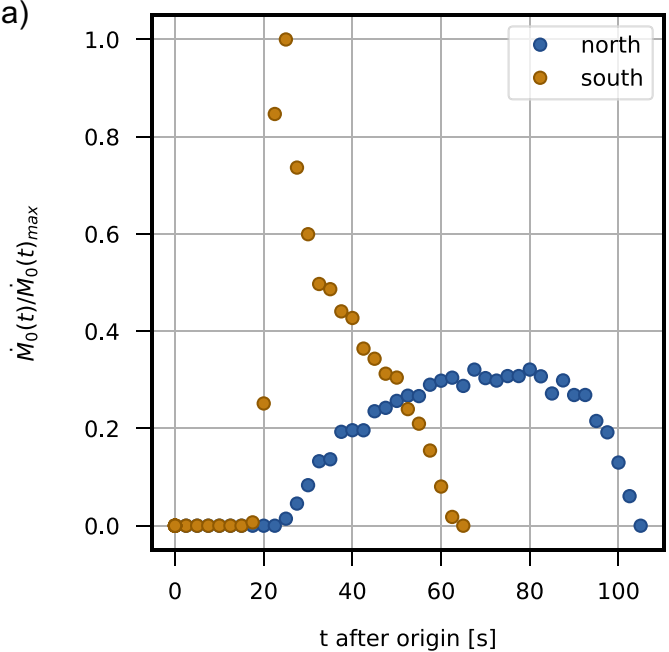

(b)

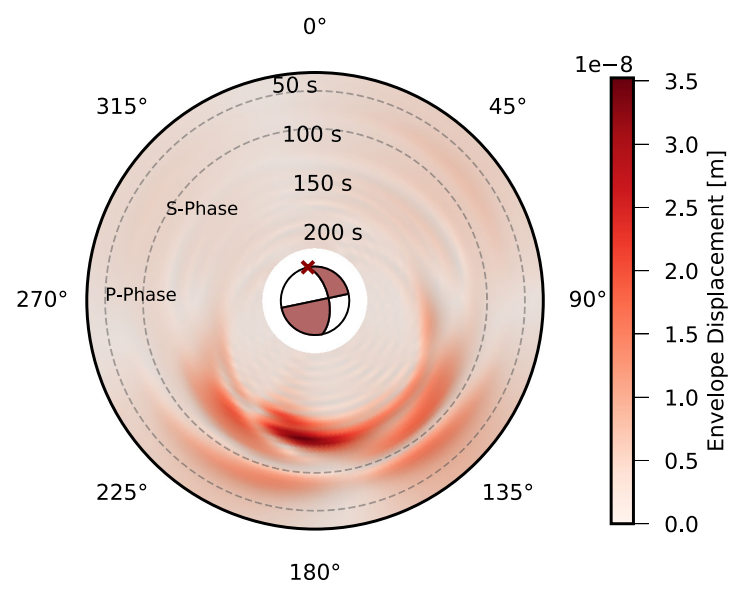

Figure 12. (a) Normalized, apparent source time function (STF) simulated in direction of the rupture front propagation (towards south, orange) and towards north (blue dots). A shorter pulse with higher amplitudes is observed for stations parallel to the fault in line with the rupture front propagation. Stations located away from the rupture front propagation show a broader (STF) with smaller amplitudes. (b) Simulated wavefield amplitudes at $400 \mathrm{~km}$ distance from the centroid as a function of azimuth (envelope displacement, lowpass filtered at $0.05 \mathrm{~Hz}$, CRUST2.0 Green's functions, R component). Theoretical P and S arrival times are indicated by dashed lines. The red cross within the source mechanism (lower hemispherical projection) indicates the position of the nucleation point relative to the centroid at the centre of the focal solution. The strike of the rupture plane can be identified by the $350^{\circ}$ striking time axis labels. The time increases from the outer border of the circle to the centre so that $\mathrm{P}$ waves are seen at a larger radius than $\mathrm{S}$ waves. 
pulse and small amplitudes. The area under both pulses is equal. The directivity effects of the apparent STF resemble theoretical expectations.

Fig. 12(b) shows the simulation of the apparent Rayleigh wave 'Mach cones' using our subshear rupture model of the 2018 Palu earthquake. The CRUST.2 waveform Green's functions have been used together with Pyrocko (Heimann et al. 2017, 2019) to simulate synthetic displacement seismograms at a regional distance of $400 \mathrm{~km}$ and various azimuths. The envelopes of lowpass filtered seismograms on the radial component $(\mathrm{R})$ are plotted. The simulation shows strongly enhanced $P$ and Rayleigh wave amplitudes under azimuths of $135^{\circ}$ and $\sim 220^{\circ}$, but not in opposite direction. This directivity pattern cannot be explained by the radiation pattern alone.

\subsection{Rupture heterogeneity}

Despite the minimalistic parametrization of the fracture, the above examples show the feasibility and flexibility of the approach to consider very different settings and earthquake scenarios. So far, we assumed a smooth, almost uniform stress drop and rupture propagation, which is well suited for the simulation of waveform effects at regional or teleseismic distances. However, the high-frequency content of near-field ground motion data often indicates that earthquake ruptures can be heterogeneous. An example for the 2015 Illapel earthquake is provided in Ruiz et al. (2016). Okuwaki et al. (2016) and Meng et al. (2018) used backprojection of high-frequency teleseismic body waves and showed that despite the simplicity of the low-frequency radiation, the high-frequency component of the Illapel's earthquake slip rate must have been very complex. We present two examples of how heterogeneities can be considered in our model with only a few parameters. First, for illustration, we simulate single, isolated asperities and barriers in circular form and how they can perturb planar rupture fronts and moment-rates. Asperities and barriers are described as areas on the rupture plane where stress or strength is enhanced or in general perturbed. Kerkhof (1969) studied the impact of isolated capillaries and circular, stiff inclusions on the dynamic propagation of a planar rupture front in glass. He employed a technique of ultrasonic modulation of the instantaneous, rupture front orientation at equidistant time steps, which is reflected in the resulting crack morphology (fractography). In these experiments a capillary was a circular area on the future rupture plane that was already broken, so that the stress (and the stress drop) was zero there itself. At and in front of the tip of the capillary, however, there were high stress singularities. The stiff inclusion, in contrary, created a stress singularity along its tip with opposite polarity, but with lower intensity. In Fig. 13, we plot the isochrones of the rupture fronts obtained in the laboratory experiments of Kerkhof (1969). All spatial and temporal perturbations are normalized to the diameter of the circular perturbation $\left(2 r_{0}\right)$ and the characteristic time needed to traverse the circular region. The velocity far before reaching the capillary is $\sim 150 \mathrm{~m} \mathrm{~s}^{-1}$. It is accelerated when approaching the capillary but retarded in the region behind the capillary until the rupture front is completely healed (Fig. 13a). Within the capillary no rupture could be tracked, as the patch is already broken. We interpret the sudden occurrence of dense 'isolines' in Fig. 13(a) after half of the capillary has been ruptured a result of frequency doubling from the nonlinear interaction of the capillary with the rupture front. The lab experiments have similarities to the 2015 Illapel earthquake, where a splitting of the high-frequency rupture front into two subfronts running along the rim of an almost circular patch, including some spots of enhanced high-frequency radiation, and their coalescence behind the 'asperity' was found (Meng et al. 2018). The effect of the stiff inclusion on rupture velocity shows the opposite pattern - the rupture front is strongly retarded just before reaching the circular, stiff barrier (high strength) but accelerated at both sides of the inclusion when passing the obstacle to generate a healed, undisturbed rupture front behind the heterogeneity (Fig. 13b). The 'roughness' of rupture front is overall smaller for the inclusion, because the rupture propagates within the barrier with the same of even a slightly larger velocity. The perturbation of the rupture front before entering the capillary or inclusion is clearly distinct from the well-established observation of unperturbed wave-fronts before entering structural heterogeneities. It is a clear example for the break-down of the simple linear scaling of rupture to shear wave velocity. The perturbation of $v_{\mathrm{r}}$ slightly outside the capillary or inclusion indicates that stress or stress gradient can modulate the background rupture velocity controlled by elastic modules

A stress modulation of $v_{\mathrm{r}}$ is also suggested from theoretical simulations and observations of quasi-static fracture growth in the neighbourhood of the free surface (Rivalta \& Dahm 2006), or close to jumps and fringe zones in desiccation cracks (Müller \& Dahm 2000), which show that the rupture front is accelerated when approaching the high stress (stress drop) region, and decelerating when leaving the high stress region or close to the high strength boundary at the fault. We use the capillary example as a model for an asperity to modulate the background rupture velocity as a function of stress around the asperity. The stress outside a penny-shaped asperity (our capillary) is described to first order by $\sigma\left(r>r_{0}\right) \sim \Delta \sigma \sqrt{r_{0}} \frac{1}{\sqrt{r-r_{0}}}$, where $r_{0}$ is the radius of the capillary and $\Delta \sigma$ is the stress drop realized on the surface of the asperity. Whether the change in stress leads to an acceleration or deceleration of rupture front depends on whether the front propagates towards or away from the high stress region. The rupture front is unperturbed if the stress gradient is perpendicular to the gradient of the rupture time (the propagation direction). The effect can be considered by the dot product between the 2-D gradient of the rupture time and stress. A linear or power-law scaling of $v_{\mathrm{r}}$ to stress can be tried to reproduce the observations in Figs 13(a) and (b). We use

$\frac{\delta v_{\mathrm{r}}}{v_{\mathrm{r}}}=f[\hat{\nabla}|\sigma| \cdot \hat{\nabla} T]|\nabla \sigma|^{p}$,

where $f$ and $p$ are determined empirically. $T\left(\xi_{1}, \xi_{2}\right)$ is the rupture time, and $\sigma\left(\xi_{1}, \xi_{2}\right)$ is the traction on the rupture plane, and $\hat{\nabla}$ is understood as unit gradient vector. The term [...] varies between -1 and +1 and accounts for the direction of the rupture front. Far from the asperity, the stress perturbation is zero, so that $\delta v_{\mathrm{r}} \rightarrow 0$.

We used the expression in eq. (4) to define a perturbed rupture velocity around the circular crack asperity. $f$ was set to $0.5, p=1 / 3$, and the maximal velocity perturbations were limited between $[0.7$, $1.3] v_{\mathrm{r}}$. The same model was used to simulate the inclusion, except that the polarity of the stress singularity was changed. Figs 13(c) and (d) show the simulation of rupture fronts in the same normalization as for the laboratory experiments by Kerkhof (1969). Starting conditions in the Eikonal solver were set to realize a planar rupture front propagating from left to right. The modelling exercise showed that the parameter $f$ and $p$ are poorly constrained in our example, but also not very critical. The largest effect is generated from setting the rupture velocity inside the asperity to zero (or a small value), so that the rupture front diffracts around the circular area and grows 
(a)

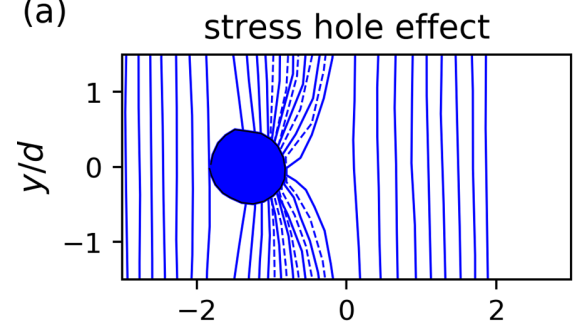

(c)

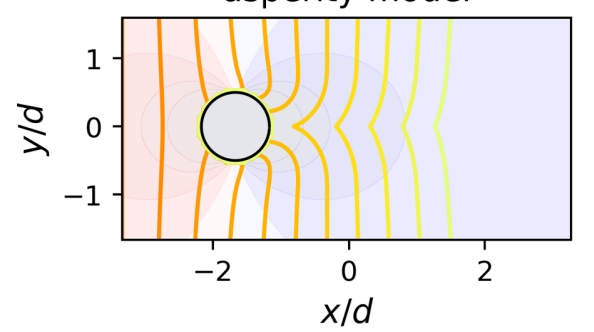

(b)

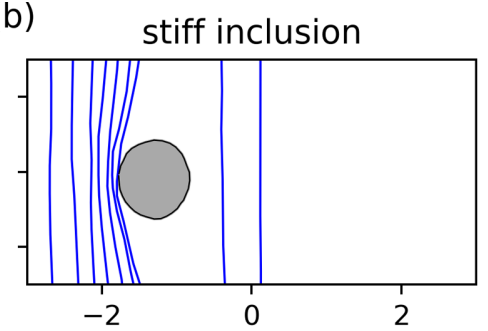

(d)

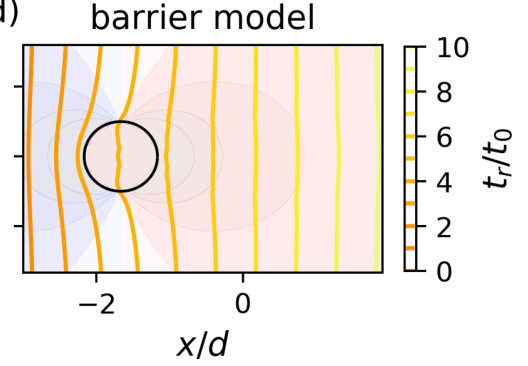

Figure 13. Observations and simulations of stress drop heterogeneities on the rupture front propagation. All features are normalized to the diameter and characteristic time of the circular heterogeneity. (a) Lab experiments in glass probe with a capillary (diameter 0.065 mm, from Kerkhof 1969) showing frozen undulations (solid lines) of the growing rupture plane at time intervals of one period of the harmonic, ultrasonic wave of 5.83 MHz. The rupture front propagated from left to right with an average velocity before reaching the capillary of $150 \mathrm{~m} \mathrm{~s}^{-1}$. The dashed lines are interpreted as non-linear frequency doubling effect resulting from the interaction of the capillary with the rupture front. (b) Results from an electronmicroscop picture of rupture fronts in Opal glass (not every cycle could be measured) retarded by a spherical, stiff inclusion $\left(\mathrm{CaF}_{2}\right.$, diameter $\left.=3.8 \mu \mathrm{m}\right)$. The harmonic ultrasonic modulation frequency was $1 \mathrm{MHz}$. The rupture propagated from left to right, the undisturbed rupture velocity is about $70 \mathrm{~cm} \mathrm{~s}^{-1}$ (from Kerkhof 1969). (c) Asperity case: simulated rupture front perturbation by assuming a circular, already broken region and a stress-dependent modulation of $v_{\mathrm{r}}$ according to eq. (4), indicated by coloured contours. Inside the asperity $v_{\mathrm{r}}$ was set to a small value. (d) Barrier case: modelling result using a similar velocity perturbation outside the circular region but inverted polarity. Inside the circle we used $v_{\mathrm{r}}=1.1 v_{0}$.

together again behind it at an acute angle. This causes roughness in slip rate, which has a stronger effect than the change of the stress drops on the asperity itself.

In Fig. 14, we compare STF and their amplitude spectra of the empirical asperity and barrier model to the spectrum of the unperturbed far-field STF. The STF of the homogeneous rupture is a smooth function in the shape of a mirrored tail fin (Fig. 14a). Its spectrum in a $\log -\log$ plot resembles a typical Brune spectrum with a low-frequency plateau, corner frequency $\left(f_{\mathrm{c}}\right)$ and high-frequency attenuation with a slope of -2 (Fig. 14b). We kept the stress drop uniform in the asperity and barrier models so that the low-frequency plateau is unchanged. Because of the acceleration and deceleration of the rupture front across the obstacle, the asperity and barrier models introduce high-frequency roughness of the STF. The effect of the asperity is much larger than for the barrier Fig. 14(a) because of the stronger curvature of rupture fronts and the cusp-like merging behind the asperity. The late arrival of energy in the asperity model is associated with the slow rupture within the asperity itself. The roughness in the STF changes the amplitude spectra of the asperity and barrier in comparison to the reference spectra. Especially for the asperity model an increase in high-frequency content is seen (Fig. 14b).

The simulation of an isolated asperity or barrier is interesting for the theoretical understanding. However, more of practical interest is the complexity of slip resulting from the distributed roughness of stress drop and rupture velocity. As we show in the example below, from a technical point of view, our rupture model can easily consider such complexity. For realization of scenario earthquake near-field ground motions often stochastic slip models are assumed. In our model context, we will prescribe a stochastic variation of stress drop on the fault, implement the $v_{\mathrm{r}}-\sigma$ relation discussed above, and simulate slip and slip rate and if necessary the resulting seismograms at stations. Following the results of Mai \& Beroza (2002), which show that slip on earthquakes often assumes a fractal distribution, we have chosen a fractal power-law approach with an exponent of -2 to define spatial perturbations of the stress drop in the range $[1,17.8] \mathrm{MPa}$. Perturbations of the rupture velocity are estimated from stress drop perturbations according to (4), where in this case an exponent of $p=1$ and a factor $f$ was selected to map the velocity perturbations to the range between 1.1 and $3.6 \mathrm{~km}$ $\mathrm{s}^{-1}$. Fig. 15 shows an example of the stochastic stress and velocity distribution and the amplitude spectra of simulated seismograms in direction of the rupture in a distance of $400 \mathrm{~km}$ and an azimuth of $33.6^{\circ}$. We note that the simulation of a stochastic rupture does not need additional computing power. While the stress variations alone have only a small influence on waveform complexity, the correlated effect of stress and rupture velocity clearly shows highfrequency energy above the nominal corner frequency of the source. For instance, the high-frequency ground motion often observed in near-field accelerograms (e.g. Ruiz et al. 2016, for Illapel) or in the backprojection of high-frequency energy in teleseismic array recordings (Okuwaki et al. 2016; Tilmann et al. 2016; Meng et al. 2018) may be modelled by such stochastic simulations. As the slip rate complexity is often observed at the downdip end of faults, the stress heterogeneity is possibly caused by the transition from locked to creeping fault segments. 

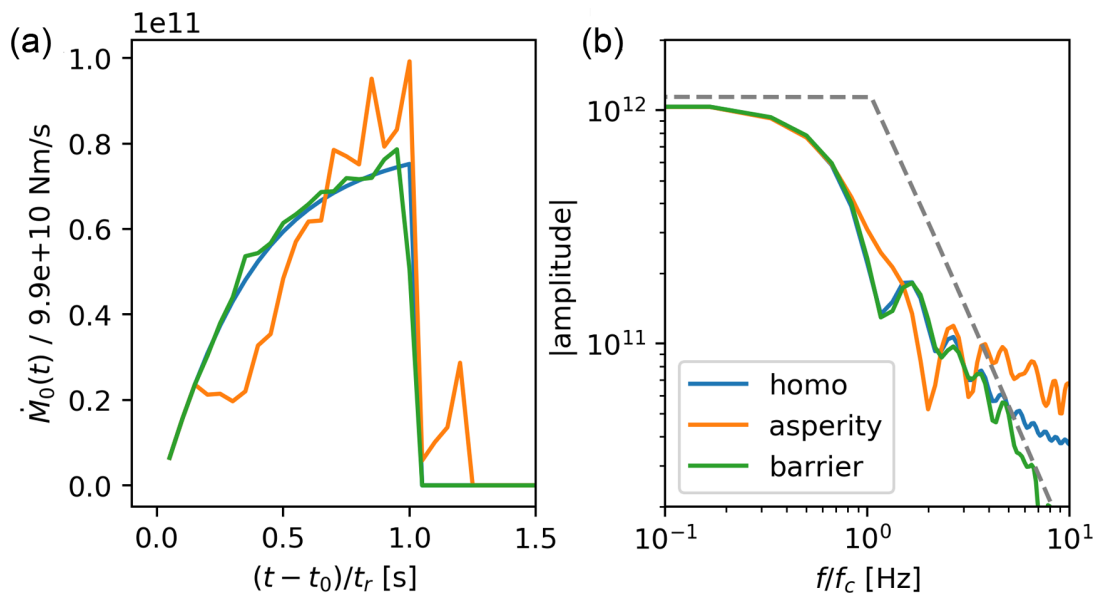

Figure 14. Full space moment rate functions (a) and the associated amplitude spectra (b) measured in the far field orthogonal to a rectangular rupture plane $(20 \mathrm{~km} \times 10 \mathrm{~km})$. The background model (homo) had a uniform rupture velocity $\left(v_{0}=1 \mathrm{~km} \mathrm{~s}^{-1}\right)$ and stress drop $(\Delta \sigma=1 \mathrm{MPa})$. Modified faults $($ asperity and inclusion model) consider a single, circular obstacle with a radius of $2 \mathrm{~km}$. The rupture velocity has been modulated ahead of the tip of the circular region (see eq. 4), while the stress drop was kept homogeneous (see Fig. 13). For the asperity, $v_{\mathrm{r}}$ inside the asperity was set to $0.1 \mathrm{~km} \mathrm{~s} \mathrm{~s}^{-1}$. The time and frequency axes are normalized by the rupture duration $t_{\mathrm{r}}=L / v_{0}=20 \mathrm{~s}$. The dashed line in (b) indicates the Brune spectra plateau and $f^{-2}$ high-frequency attenuation.
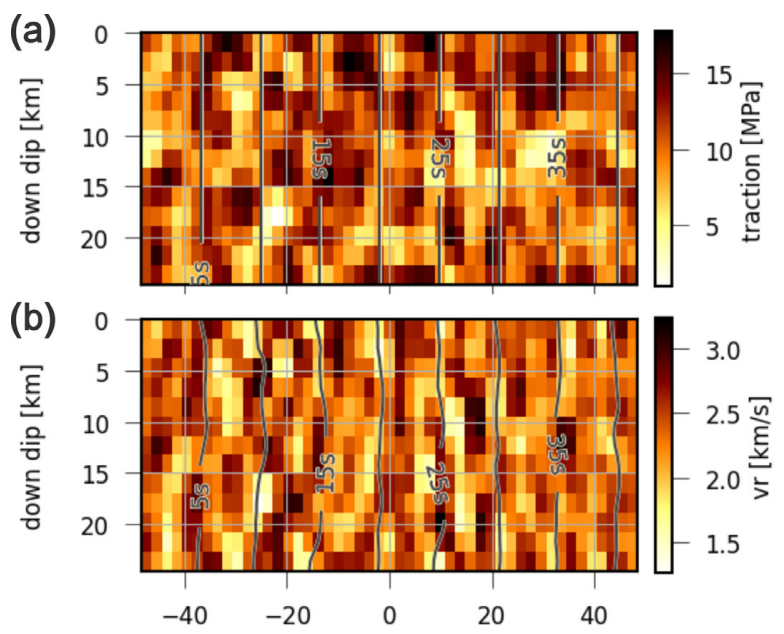

along strike $[\mathrm{km}]$

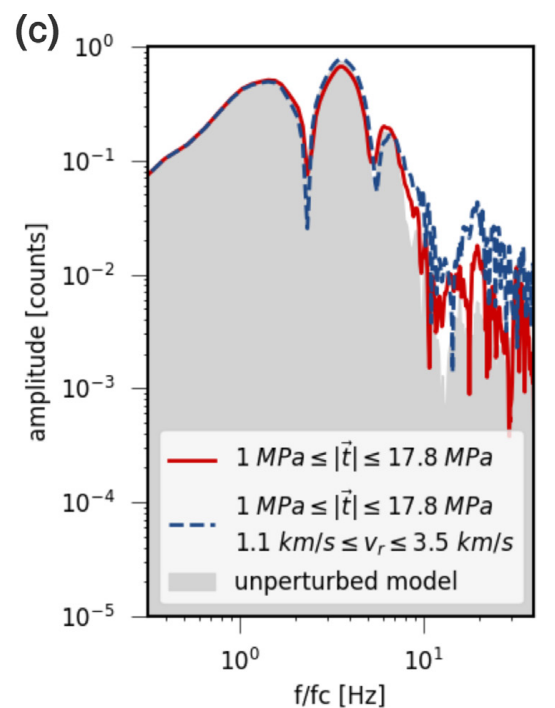

Figure 15. Simulation of stochastic rupture models of a vertical strike-slip fault, where stress drop was varied isolated (a) or strongly correlated to rupture velocity (b). For the latter, the scalar product of the traction gradient and the initial velocity vector is scaled to the given rupture velocity ranges and added onto the initial velocity field. The initial model has a homogeneous traction of $10 \mathrm{MPa}$ in strike direction and a homogeneous rupture velocity field of $2.25 \mathrm{~km} \mathrm{~s}^{-1}$. The range of traction and velocity variations is given in the legend. (c) Shown are the amplitude spectra of displacement records ( $Z$ component) at a station in direction of the unilatetal rupture in a distance of $400 \mathrm{~km}$ and an azimuth of $33.6^{\circ}$ from the rupture top centre point. The unperturbed model spectrum is plotted as grey region. For comparison, the individual effect of a complex traction only (red line) and a complex traction correlated to rupture velocity (blue dashed line) are shown.

\section{CONCLUSIONS}

We implemented a self-similar fracture model for arbitrarily complex forms of the fracture front, which decouples the propagation of the fracture from the slip. The approach is computationally extremely efficient and comprises only three free parameters in addition to a point source earthquake model. At the same time it is very flexible and capable of modelling fractures and earthquake ruptures for different tectonic setting and faults in the crust and mantle. The model uses approximate relations in some parts, while exact solutions are used in other parts. For example, the propagation of the rupture front is approximated by a wave-rupture analogy, which, although not exact, is usually sufficient for the purpose of kinematic or dynamic fracture modelling. It is assumed that the rupture velocity scales to the lithospheric shear wave velocity. The instantaneous dislocation and slip on the fault is modelled exactly by means of a numerical boundary element scheme. The stress drop is given as a static input field and can be retrieved from a background stress model together with assumptions about the frictional strength at a fault with given orientation. It was found that the self-similar dynamic model explains the main low-frequency features observed during the earthquake rupture, as for example,

(1) a self-development (without external input or constraint) of circular, elliptical or rectangular ruptures with circular, bilateral or unilateral propagation at the front;

(2) a natural transition from crack-like to pulse-like rupture slipmode in large crustal faults; 
(3) the development of high slip patches close to the surface or within stress drop asperities;

(4) the penetration of slip into boundary layers of low or zero stress because of the self-stressing effect of fractures;

(5) the effect of apparent backward propagation of slip where stress drop heterogeneities exist;

(6) the development of curved and planar rupture fronts up to refracted fronts propagating with an apparent horizontal super-shear velocity;

(7) the directivity effects on waveforms including apparent Rayleigh wave Mach cones;

(8) the natural development (without controlling parameter) of a space-dependent rise time and source time function.

The method can also be used to study rupture complexity and high-frequency energy radiation if the stress field prescribed on the rupture plane is heterogeneous. We showed an example to simulate effects from isolated asperities and barriers. A second example considers a stochastic slip model where we coupled stress heterogeneity to rupture velocity perturbations. Such approaches may be interesting to study the high-frequency components of slip-rate, as e.g. observed in near-field accelerograms.

The simplified dynamic source parametrization is suited for fast numerical modelling and probabilistic inversion approaches in source seismology. For this purpose, the model has been fully integrated into an open source toolbox for seismology (Pyrocko, https://git.pyrocko.org/pyrocko/pyrocko) and probabilistic source inversions (Grond), which are directly linked to a system of static and dynamic wavefield Green's function databases. Examples of Python scripts are provided at https://pyrocko.org/docs/ under pseudo-dynamic rupture. The applications are therefore easy to implement and reproduce. The tools can be used for the study of earthquakes, but also for other rupture and fracture phenomena such as hydrofracking, magmatic dike intrusion or aseismic fracture growth. We would like to point out that the strengths of the simplified model lie in its simplicity and the few parameters it comprises. However, it cannot replace a complete dynamic fracture modelling, which is necessary to understand the complexity of the rupture, including the high-frequency emission of waves.

\section{ACKNOWLEDGEMENTS}

MM has been supported by the BMBF project EWRICA (03G0891A). MI thanks Dr Henriette Sudhaus and acknowledges funding by the German Research Foundation DFG through an Emmy-Noether Young-Researcher-Grant (276464525) and from the BMWi though project DEEPEN. We would like to thank two reviewers and the editor for their reviews and suggestions to improve the manuscript.

Author contributions statement: TD and SH developed the concept and theory of the self-similar rupture model. TD drafted the manuscript and initial figures and wrote a first version of the manuscript. SH coded the Eikonal solver and implemented this into the Pyrocko framework. MM, SH and MI developed a 3D BEM code and implemented this into Pyrocko GF database. MI improved the performance of the slip inversion within Pyrocko, and prepared man pages and cookbook examples. MM run basic validation and verification tests, run the final simulations and generated most of the figures. All authors contributed to writing.

\section{REFERENCES}

AIST, 2012. Active Fault Database of Japan, Research information database db095, National Institute of Advanced Industrial Science and Technology.

Aki, K., 1966. Generation and propagation of $G$ waves from the Niigata earthquake of June 1964, Bull. Earthq. Res. Inst., Univ. Tokyo, 44, $23-88$.

Asano, K. \& Iwata, T., 2016. Source rupture processes of the foreshock and mainshock in the 2016 Kumamoto earthquake sequence estimated from the kinematic waveform inversion of strong motion data, Earth Planets Space, 68(147), doi:10.1186/s40623-016-0519-9.

Bao, H., Ampuero, J.P., Meng, L., Fielding, E.J., Liang, C., Milliner, C.W., Feng, T. \& Huang, H., 2019. Early and persistent supershear rupture of the 2018 magnitude 7.5 Palu earthquake, Nat. Geosci., 12(3), 200-205.

Bassin, C., Laske, G. \& Masters, G., 2000. The current limits of resolution for surface wave tomography in North America, EOS, Trans. Am. geophys. Un., 81(48), F897.

Beresnev, I., 2003. Uncertainties in finite-fault slip inversions: to what extend to believe? (a critical review), Bull. seism. Soc. Am., 93, 2445-2458.

Brune, J., 1970. Tectonic stress and the spectra of seismic shear waves from earthquakes, J. geophys. Res., 75, 4997-5007.

Brune, J., 1971. Correction to: "Tectonic stress and the spectra of seismic shear waves from earthquakes", J. geophys. Res., 76, 5002.

Buijze, L., Van den Bogert, P.A.J., Wassing, B.B.T. \& Orlic, B., 2019. Nucleation and arrest of dynamic rupture induced by reservoir depletion, $J$. geophys. Res., 124, 3620-3645,

Cesca, S., Dahm, T., Juretzek, K. \& Kühn, D., 2011a. Rupture process of the 7 May 2011, $M_{\mathrm{w}}$ 4.2, Ekofisk induced earthquake, Geophys. J. Int., doi:10.1111/j.1365-246X.2011.05151.x.

Cesca, S., Grigoli, F., Heimann, S., Dahm, T., Kriegerowski, M., Sobiesiak, M., Tassara, C. \& Olcay, M., 2016. The $M_{\mathrm{w}} 8.12014$ Iquique, Chile, seismic sequence: a tale of foreshocks and aftershocks, Geophys. J. Int., 204(3), 1766-1780.

Cesca, S., Heimann, S. \& Dahm, T., 2011b. Rapid directivity detection by azimuthal amplitude spectra inversion, J. Seismol., 15, 147-164.

Contreras-Reyes, E., Maksymowicz, A., Lange, D., Grevemeyer, I., MuñozLinford, P. \& Moscoso, E., 2017. On the relationship between structure, morphology and large coseismic slip: a case study of the $M_{\mathrm{W}} 8.8$ Maule, Chile 2010 earthquake, Earth planet. Sci. Lett., 478, 27-39.

Dahm, T., 2000. Numerical simulations of the propagation path and the arrest of fluid-filled fractures in the earth, Geophys. J. Int., 141, 623-638.

Dahm, T., Cesca, S., Hainzl, S., Braun, T. \& Krger, F., 2015. Discrimination between induced, triggered, and natural earthquakes close to hydrocarbon reservoirs: a probabilistic approach based on the modeling of depletioninduced stress changes and seismological source parameters, J. geophys. Res., 120(2), 2491-2509.

Dahm, T., Hainzl, S. \& Fischer, T., 2010. Bidirectional and unidirectional fracture growth during hydrofracturing: role of driving stress gradients, Geophys. J. Int., 115(18pp), doi:10.1029/2009JB006817.

Dahm, T. \&Krüger, 2012. Moment tensor inversion and moment tensor interpretation, in New Manual of Seismological Observatory Practice (NMSOP-2), pp. 1-37, ed. Bormann, P.E., Deutsches GeoForschungsZentrum GFZ.

DeGraff, J. \& Aydin, A., 1987. Surface morphology of columnar joints and its significance to mechanics and direction of joint growth, Bull. geol. Soc. Am., 99, 605-6127.

Duan, B., 2010. Role of initial stress rotation in rupture dynamics and ground motion: a case study with implications for the Wenchuan earthquake, $J$. geophys. Res., 115, B05301, doi:10.1029/2009JB006750.

Fang, J., Xu, C., Wen, Y., Wang, S., Xu, G., Zhao, Y. \& Yi, L., 2019. The $2018 M_{\mathrm{W}} 7.5$ Palu earthquake: a supershear rupture event constrained by InSAR and broadband regional seismograms, Remote Sens., 11(11), $1-15$.

Fuentes, M., Riquelme, S., Hayes, G., Medina, M., Melgar, D., Vargas, G., González, J. \& Villalobos, A., 2016. A study of the $2015 M_{\mathrm{W}} 8.3$ Illapel earthquake and tsunami: numerical and analytical approaches, Pure appl. Geophys., 173(6), 1847-1858.

Gallis, M., Ampuero, J., Mai, P. \& Cappa, F., 2017. Sci. Adv., 3, 1-10. 
Haskell, N., 1964. Total energy spectral density of elastic waves radiation from propagating faults, Bull. Seism. Soc. Am., 54, 1811-1841.

Haskell, N., 1966. Total energy and energy spectral density of elastic wave radiation from propagating faults. Part II. A statistical source model, Bull. seism. Soc. Am., 56, 125-14041.

Haskell, N., 1969. Elastic displacements in the near field of a propagating fault, Bull. seism. Soc. Am., 59, 865-908.

Hayes, G.P., 2017. The finite, kinematic rupture properties of great-sized earthquakes since 1990, Earth planet. Sci. Lett., 468, 94-100.

Heidbach, O. et al., 2018. The world stress map database release 2016: crustal stress pattern across scales, Tectonophysics, 744, 484-498.

Heimann, S., 2010. A robust method to estimate kinematic earthquake source parameter, PhD thesis, Institut für Geophysik, Universität Hamburg.

Heimann, S., Vasyura-Bathke, H., Sudhaus, H., Paul Isken, M., Kriegerowski, M., Steinberg, A. \& Dahm, T., 2019. A Python framework for efficient use of pre-computed Green's functions in seismological and other physical forward and inverse source problems, Solid Earth, (10), 1921-1935

Heimann, S. et al., 2017. Pyrocko-an open-source seismology toolbox and library, V. 0.3, GFZ Data Services, doi:10.5880/GFZ.2.1.2017.001.

Heimann, S. et al., 2018. Grond - A probabilistic earthquake source inversion framework. V. 1.0. GFZ Data Services, doi:10.5880/GFZ.2.1.2018.003.

Helgeson, D. \& Aydin, A., 1991. Characteristics of joint propagation across layer interfaces in sedimentary rocks, J. Struct. Geol., 13, 897-911.

Herman, M.W., Nealy, J.L., Yeck, W.L., Barnhart, W.D., Hayes, G.P., Furlong, K.P. \& Benz, H.M., 2017. Integrated geophysical characteristics of the 2015 Illapel, Chile, earthquake, J. geophys. Res., 122(6), 4691-4711.

Jamelot, A., Gailler, A., Heinrich, P., Vallage, A. \& Champenois, J., 2019. Tsunami simulations of the Sulawesi $M_{\mathrm{w}} 7.5$ event: comparison of seismic sources issued from a Tsunami warning context versus post-event finite source, Pure appl. Geophys., 176, 3351-3376.

Jost, M. \& Herrman, R., 1989. A students guide to and review of moment tensors, Seismol. Res. Lett., 60, 37-57.

Kanamori, H., 1994. Mechanics of Earthquakes, Annu. Rev. Earth planet. Sci., 22(1), 207-237.

Kanamori, H. \& Anderson, D.L., 1975. Theoretical basis of some empirical relations in seismology, Bull. seism. Soc. Am., 65(5), 1073-1095.

Kaneko, Y., Avouac, J. \& Lapusta, N., 2010. Towards inferring earthquake patterns from geodetic observations of interseismic coupling, Nat. Geosci., 3, 363-369.

Kato, A., Nakamura, K. \& Hiyama, Y., 2016. The 2016 Kumamoto earthquake sequence, Proc. Japan Acad. B, 92(8), 358-371.

Kennett, B.L.N., Engdahl, E.R. \& Buland, R., 1995. Constraints on seismic velocities in the Earth from traveltimes, Geophys. J. Int., 122(1), $108-124$.

Kerkhof, F., 1969. Einführung in die Bruchmechanik, Ernst-Mach-Institut der Fraunhofer Gesellschaft.

Kostrov, B., 1964. Self-similar problems of propagation of shear cracks, $J$. Appl. Math. Mech., 28, 1077-1087.

Kubo, H., Suzuki, W., Aoi, S. \& Sekiguchi, H., 2016. Source rupture processes of the 2016 Kumamoto, Japan, earthquakes estimated from strongmotion waveforms, Earth Planets Space, 68(1), 1-13.

Kulander, B. \& Dean, S., 1995. Observations on fractography with laboratory experiments for geologists, in Fracture Topography as a Tool in Fracture Mechanics and Stress Analysis, Vol. 92, pp. 59-82, ed. Ameen, M., Geol. Soc. Spec. Publ.

Laske, G.,Masters. G., Ma, Z. \& Pasyanos, M., 2013. Update on CRUST1.0 - a 1-degree global model of Earth's crust, in EGU General Assembly 2013, Vienna, Austria, EGU2013-2658.

Lin, A., Satsukawa, T., Wang, M., Mohammadi Asl, Z., Fueta, R. \& Nakajima, F., 2016. Coseismic rupturing stopped by Aso volcano during the $2016 M_{\mathrm{w}} 7.1$ Kumamoto earthquake, Japan, Science, 354(6314), 869874.

Lopez-Comino, J. \& Cesca, S., 2016. Source Complexity of an injection induced event: the $2016 M_{\mathrm{w}} 5.1$ Fairview, Oklahoma earthquake, Geophys. Res. Lett., 45, 4025-4032.
Lui, S.K. \& Huang, Y., 2019. Do injection-induced earthquakes rupture away from injection wells due to fluid pressure change?, Bull. seism. Soc. Am., 109, 358-371.

Madariaga, R., Olsen, K. \& Archuleta, R., 1998. Modeling dynamic rupture in a 3D earthquake fault model, Bull. seism. Soc. Am., 88, 1182-1197.

Mai, M. \& Beroza, G., 2002. A spatial field model to characterize complexity in earthquake slip, J. geophys. Res., 107, doi:10.1029/2001JB000588.

Mai, M. et al., 2016. The earthquake source inversion validation (SIV) project, Seismol. Res. Lett., 87, 690-708.

Maksymowicz, A., Tréhu, A.M., Contreras-Reyes, E. \& Ruiz, S., 2015. Density-depth model of the continental wedge at the maximum slip segment of the Maule $M_{\mathrm{w}} 8.8$ megathrust earthquake, Earth planet. Sci. Lett., 409, 265-277.

Melgar, D. et al., 2016. Slip segmentation and slow rupture to the trench during the 2015, $M_{\mathrm{w}} 8.3$ Illapel, Chile earthquake, Geophys. Res. Lett., 43(3), 961-966.

Meng, L., Baoa, H., Huanga, H., Zhanga, A., Bloorea, A. \& Liub, Z., 2018. Double pincer movement: encircling rupture splitting during the $2015 M_{\mathrm{W}}$ 8.3 Illapel earthquake, Earth planet. Sci. Lett., 495, 164-173.

Menke, W., 1989. Geophysical Data Analysis: Discrete Inverse Theory, revised edition, Academic Press Inc.

Metois, M., Socquet, A. \& Vigny, C., 2012. Interseismic coupling, segmentation and mechanical behavior of the central Chile subduction zone, $J$. geophys. Res., 1-16, doi:10.1029/2011JB008736.

Metz, M., 2019. A quasi-dynamic and self-consistent rupture model to simulate earthquake ruptures, Master's thesis, University Potsdam.

Minson, S., Simons, M. \& Geck, J., 2013. Bayesian inversion for finite fault earthquake source models I—-theory and algorithm, Geophys. J. Int., 194, $1701-1726$

Moore, J.D.P. et al., 2017. Imaging the distribution of transient viscosity after the $2016 M_{\mathrm{w}}$ 7.1 Kumamoto earthquake, Science, 356(6334), 163-167.

Müller, G. \& Dahm, T., 2000. Fracture morphology of tensile cracks and rupture velocity, J. geophys. Res., 105, 723-738.

Nielsen, S. \& Carlson, J., 2000. Rupture pulse characterization: self-healing, self-similar, expanding solutions in a continuum model of fault dynamics, Bull. seism. Soc. Am., 90, 1480-1497.

Nielsen, S. \& Madariaga, R., 2003. On the self-healing fracture mode, Bull. seism. Soc. Am., 93, 2375-2388.

Ohnaka, M., 2013. The Physics of Rock Failure and Earthquakes, Cambridge Univ. Press.

Okada, Y., 1992. Internal deformation due to shear and tensile faults in a half-space, Bull. seism. Soc. Am., 82, 1018-1040.

Okuwaki, R., Hirano, S., Yagi, Y. \& Shimizu, K., 2020. Inchworm-like source evolution through a geometrically complex fault fueled persistent supershear rupture during the 2018 Palu Indonesia earthquake, Earth planet. Sci. Lett., 547, doi:10.1016/j.epsl.2020.116449.

Okuwaki, R., Yagi, Y., Arangui, A., Juan Gonzalez, J. \& Gonzalez, G., 2016. Rupture process during the 2015 Illapel, Chile earthquake: zigzag-alongdip rupture episodes, Pure appl. Geophys., 173, 1011-1020.

Oth, A., Miyake, H. \& Bindi, D., 2017. On the relation of earthquake stress drop and ground motion variability, J. geophys. Res., 122(7), 5474-5492.

Ozawa, T., Fujita, E. \& Ueda, H., 2016. Crustal deformation associated with the 2016 Kumamoto earthquake and its effect on the magma chamber of Aso volcano, in Japan Geoscience Union Meeting, Chiba, Japan, MIS34P42.

Pollard, D. \& Segall, P., 1987. Theoretical displacements and stresses near fractures in rock: with application to faults, joints, veins, dikes, and solution surfaces, in Fracture Mechanics of Rocks, pp. 277-347, ed. Atkinson, B., Academic Press INC.

Rivalta, E. \& Dahm, T., 2006. Acceleration of buoyancy-driven fractures and magmatic dikes beneath the free surface, Geophys. J. Int., 166, 1424 1439.

Rowshandel, B., 2006. Incorporating source rupture characteristics into ground-motion hazard analysis models, Seismol. Res. Lett., 77(6), 708722.

Ruiz, S. et al., 2016. The seismic sequence of the 16 September $2015 M_{\mathrm{W}}$ 8.3 Illapel, Chile, earthquake, Seismol. Res. Lett., 87, 789-799. 
Rummel, F., 1987. Fracture mechanics approach to hydraulic fracturing stress measurements, in Fracture Mechanics of Rocks, pp. 217-239, ed. Atkinson, B., Academic Press INC.

Sato, T. \& Hirasawa, T., 1973. Body wave spectra from propagating shear cracks, J. Phys. Earth, 21, 415-431.

Sethian, J., 1996. A fast marching level set method for monochromatic advancing fronts, Proc. Natl. Acad. Sci. USA, 93, 1591-1595.

Shimizu, K., Yagi, Y., Okuwaki, R. \& Fukahata, Y., 2020. Development of an inversion method to extract information on fault geometry from teleseismic data, Geophys. J. Int., 220, 1055-1065.

Socquet, A., Hollingsworth, J., Pathier, E. \& Bouchon, M., 2019. Evidence of supershear during the 2018 magnitude 7.5 Palu earthquake from space geodesy, Nat. Geosci., 12, 192-199.

Somerville, P., Smith, N., Graves, R.W. \& Abrahamson, N.A., 1997. Modification of empirical strong ground motion attenuation relations to include the amplitude and duration effects of rupture directivity, Seismol. Res. Lett., 68, 199-222.

Song, X., Zhang, Y., Shan, X., Liu, Y., Gong, W. \& Qu, C., 2019. Geodetic observations of the $2018 M_{\mathrm{W}} 7.5$ Sulawesi earthquake and its implications for the kinematics of the Palu fault, Geophys. Res. Lett., 46(8), 4212-4220.

Tago, J., Cruz-Atienza, V., Virieux, J., Etienne, V. \& Sanches-Sesma, F., 2012. A 3D hp-adaptive discontinuous Galerkin method for modeling earthquake dynamics, J. geophys. Res., 117, doi:10.1029/2012JB009313.

Tilmann, F. et al., 2016. The 2015 Illapel earthquake, central Chile, a type case for a characteristic earthquake? Geophys. Res. Lett., 43, 1-26.

Ulrich, T. et al., 2019. Coupled, physics-based modeling reveals earthquake displacements are critical to the 2018 Palu, Sulawesi tsunami, Pure appl. Geophys., 176, 4069-4109.

Vasyura-Bathke, H., Dettmer, J., Dutta, R., Mai, P.M. \& Jónsson, S., 2021. Accounting for theory errors with empirical Bayesian noise models in nonlinear centroid moment tensor estimation, doi:10.1093/gji/ggab034, 0956-540X.

Weinberger, R., 1999. Initiation and growth of cracks during dessication of stratified muddy sediments, J. Struct. Geol., 21, 3381-3396.

Wortel, M. \& Cloetingh, S., 1985. Accretion and lateral variations in tectonic structure along the Peru-Chile trench, Tectonophysics, 112(1), 443-462.

Yagi, Y. \& Fukahata, J., 2011. Introduction of uncertainty of Greens function into waveform inversion for seismic source processes, Geophys. J. Int., 186, doi:10.1111/j.1365-246X.2011.05043.x.
Yagi, Y., Okuwaki, R., Enescu, B., Kasahara, A., Miyakawa, A. \& Otsubo, M., 2016. Rupture process of the 2016 Kumamoto earthquake in relation to the thermal structure around Aso volcano, Earth Planets Space, 68(118), doi:10.1186/s40623-016-0492-3.

Yano, T. \& Matsubara, M., 2016. The significance of seismicity after the 2016 Kumamoto earthquake sequence, in Japan Geoscience Union Meeting, Chiba, Japan, MIS34-P05.

Yarai, H. et al., 2016. Crustal deformation of the 2016 Kumamoto earthquake, in Japan Geoscience Union Meeting, Chiba, Japan, MIS34-03.

Ye, L., Lay, T., Kanamori, H. \& Koper, K.D., 2016. Rapidly estimated seismic source parameters for the 16 September 2015 Illapel, Chile $M_{\mathrm{w}}$ 8.3 earthquake, Pure appl. Geophys., 173(2), 321-332.

Yolsal-Çevikbilen, S. \& Taymaz, T., 2019. Source characteristics of the 28 September $2018 M_{\mathrm{w}} 7.5$ Palu-Sulawesi, Indonesia (SE Asia) earthquake based on inversion of teleseismic bodywaves, Pure appl. Geophys., 176(10), 4111-4126.

\section{SUPPORTING INFORMATION}

Supplementary data are available at $G J I$ online.

Figure S1. Flowchart illustrating the input and output, the parametrization and the computation of the pseudo-dynamic rupture model.

Figure S2. Comparison of moment rate snapshots for the 2018 Palu earthquake assuming (a) a shallow (19 km) and (b) a deep (28 km) nucleation point depth (see Table 3).

Figure S3. Final static slip results from the inversion in Jamelot et al. (2019) (a) and our forward modelling results (b) for the 2018 Palu earthquake. Slip is colour-coded and contour lines indicate the rupture front arrival time (in panel $b$ for our model). The red point indicates the nucleation point used in our model.

Please note: Oxford University Press is not responsible for the content or functionality of any supporting materials supplied by the authors. Any queries (other than missing material) should be directed to the corresponding author for the paper. 